\title{
PREDICTIONS AND ACCEPTANCE CRITERIA FOR K REACTOR STARTUP AND POWER ASSENSION ADDENDUM 1
}

by

R. A. Bond, Jr.

Westinghouse Savannah River Company

Savarnah River Site

Aiken, South Carolina 29808

$$
\text { UL. : }: 1992
$$

The information contained in this document was prepared in connection with work done under Contract No. DE-AC09-89SR 18035 with the U.S. Department of Energy. By acceptance of this report, the publisher and/or recipient acknowledges the U.S. Government's right to retain a nonexclusive, royalty-free license in and to any copyright covering this report, along with the right to reproduce and to authorize others to reproduce all or part of the copyrighted report. 


\section{DISCLAIMER}

This report was prepared as an account of work sponsored by an agency of the United States Government. Neither the United States Government nor any aggency thereof, nor any of their employees, makes any warranty, express or implied, or assumes any legal liability or responsibility for the accuracy, completeness, or usefulness of any information, apparatus, product, or process disclosed, or represents that its use would not infringe privately owned rights. Reference herein to any specific commercial product, process, or service by trade name, trademark, manufacturer, or otherwise does not necessarily constitute or imply its endorsement, recommendation, or favoring by the United States Government or any agency thereof. The views and opinions of authors expressed herein do not necessarily state or reflect those of the United States Government or any agency thereof.

This report has been reproduced directly from the best available copy.

Available to DOE and DOE contractors from the Office of Scientific and Technical Information, P.O. Box 62, Oak Ridge, TN 37831; prices available from (615) 576-8401, FTS 626-8401.

Available to the public from the National Techncial Information Service, U.S. Department of Commerce, 5285 Port Royal Rd., Springfield, VA 22161. 


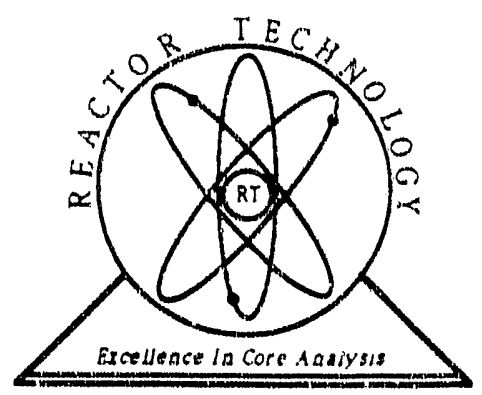

WSRC-TR-91-42-043

Addendum 1

DOES NOT CONTAIN

UNCLASSIFED CONTROLLED

NUCLEAR INFORMATION

\section{PREDICTIONS AND ACCEPTANCE CRITERIA FOR K REACTOR STARTUP AND POWER ASCENSION (U) ADDENDUM 1}

BY:

R. A. BOND, JR.

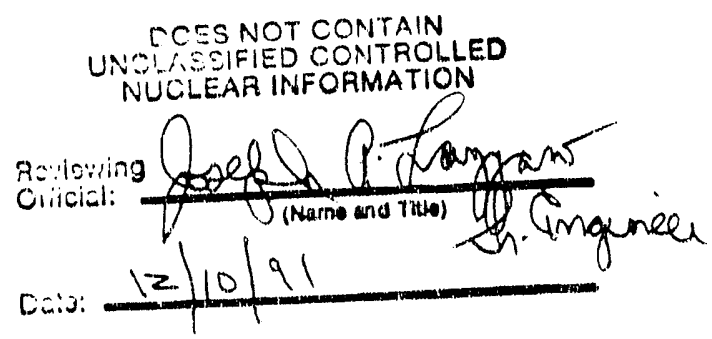

OCTOBER 21, 1991

REACTOR TECHNOLOGY SECTION REACTOR ENGINEERING DEPARTMENT

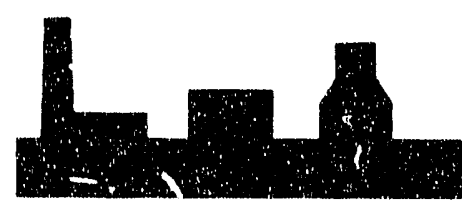


REACTOR TECHNOLOGY SECTION

REACTOR ENGINEERING DEPARTMENT

DOES NOT CONTAIN

UNCLASSIFIED CONTROLLED

NUCLEAR INFORMATION

Reviewing

Official:

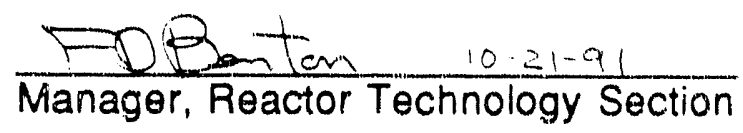

WSRC-TR-91-42.043, Addendum 1

KEYWORDS:

STARTUP TESTING

K-14 MARK 22 CHARGE CONTROL ROD WORTH GLASS

GRIMHX

RETENTION:

PERMANENT

CLASSIFICATION:

Unclassified

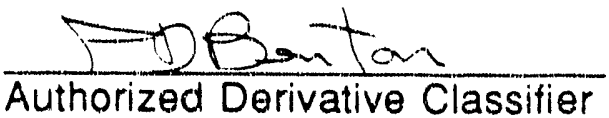

\section{PREDICTIONS AND ACCEPTANCE CRITERIA FOR $K$ REACTOR STARTUP AND POWER ASCENSION (U) ADDENDUM 1}

BY:

R. A. BOND, JR.

ISSUED: OCTOBER 21, 1991
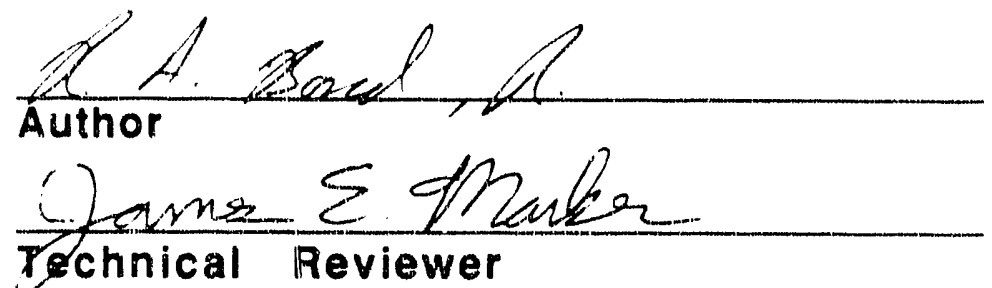

Mace Ressen

DD Qenton

Manager, Reactor Technology
DATE:, $0 / 21 / 91$

DATE: 21 CCT 91

DATE: $10 / 21 / 91$

DATE: $|0-21-9|$ 
WSRC-TR-91-42-043, Addendum 1

Page 1 of 42

October 21, 1991

\section{PREDICTIONS AND ACCEPTANCE CRITERIA FORK BEACTOR STARTUP AND POWER ASCENSION. ADDENDUM 1 (U)}

\section{INTRODUCTION}

Calculations have been performed to determine the reactivity worth of various partial rod movements to be performed in the K-14 Startup and Power Ascension Test Program. Some tests have been revised since the issuance of the predictions and acceptance criteria for the startup/power ascension testing procedure, RSP 90-007 1. The tests were modified to account for changes in the Technical Specifications concerning control rod positioning. This addendum describes the changes to the test configurations and documents the revised expectation values for the partial rod insertion tests. Additional calculations were performed to cover the complete range of possible full rod positions at the zero power testing level.

\section{SUMMARY}

Recent changes to Technical Specifications on control rod positioning have disallowed the use of integral rods, restricted the positioning of partial rods to between $700 \mathrm{vu}$ and $950 \mathrm{vu}$, and changed the power level at which flux shapes must be controlled2. These Tech Spec changes impacted four tests within the startup procedure, RSP 90-007. In order to remain within Technical Specifications during startup testing, the proposed integral rod insertion test was eliminated and the three partial rod insertion tests were modified to allow them to be performed within the limits of the Technical Specifications. The single partial rod insertion test at zero power was modified to limit the rod insertion to $950 \mathrm{vu}$ instead of $1000 \mathrm{vu}$. The single partial rod insertion test at power was modified in the same manner. The single partial rod and gang partial rod insertion tests at power were modified to be performed at a lower power where flux shapes would not be lirniting. The expectation values for the single partial rod insertion tests are shown in Figures $1-12$. The 
WSRC-TR-91-043, Addendum i

Page 2 of 42

October 21, 1991

expectation values for the gang partial rod insertion tests are shown in Figures $13-27$.

The acceptance criteria and predictions for RSP 90-007-05, Differential Rod Worth Measurements, have been expanded. The predictions now cover the full rod position limits on initial criticality as described in the Technical Specifications. RSP 90-007-05 will be modified to include Figures 28 - 37. No procedural step changes will be required for these modifications.

\section{DISCUSSION}

\section{Lntegral Rod Insertion Test}

Technical Specification 3.2.1 states that no full rod shall be inserted as an integral rod2. The reactivity change and power perturbation of an integral rod insertion was to be measured in RSP 90-007-10. Because of the Tech Spec restriction, this section of RSP 90-007 will be removed and the test will not be performed.

\section{Single Partial Red Insertion Tests}

Technical Specification 3.2.2 states that partial rod positions in every cluster that is not voided of partial rods will be between 700 vu and 950 $v^{2}$. Two sections of RSP 90-007 were to measure the effect of inserting a single partial rod from 800 vu to 1000 vu. RSP 90-007-07 was to measure the reactivity effect of inserting a weak partial and strong partial rod individually at zero power. RSP 90-007-11 was to measure at $60 \%$ power the reactivity effect and power perturbation caused by the same partial rods measured in RSP 90-007-07. To accommodate the Tech Spec changes, these tests were modified to only insert the partial rods from 800 vu to $950 \mathrm{vu}$.

RSP 90-007-07 will be modified to measure the reactivity effect of inserting a single partial rod from 800 vu to $950 \mathrm{vu}$ (rather than 800 vu to $1000 \mathrm{vu}$ ) while the reactor is operating in the zero power testing range $(40 \mathrm{~kW}$ to $120 \mathrm{~kW})$. The full rods in each gang will be at the same insertion. Single partial rods will be inserted in control clusters 1,36 , and 52 individually. Reactivity changes will be measured with the reactivity computer. Calculations were performed to predict the 
WSRC-TR-91-043, Addendum 1

Page 3 of 42

October 21, 1991

reactivity worth of the weak partial and strong partial rod moves individually. The revised expectation values for the particular partial rod insertions are shown in Figures $1-12$.

RSP 90-007-11 will be modified to measure the reactivity effect and the power perturbation caused by the insertion of partial rods (same as in RSP 90-007-07) while the reactor is operating below the Instrument Shape Applicability Limit (ISAL) rather than $60 \%$ of full power. With the reactor operating below ISAL and the full rods in each gang at the same insertion, the Technical Specifications have no requirements on flux shape ${ }^{2}$. The Technical Specifications do require that the partial rods remain between $700 \mathrm{vu}$ and $950 \mathrm{vu}$. Since the full rod insertion will be the same in each gang, the same figures used in RSP 90-007-07 (Figures 1 - 12) can be used for acceptance criteria in this test. The reactivity effect of the single partial rod insertions will be measured by the change in the full rod positions to maintain the reactor power level. The power perturbations will be measured by the change in assembly effluent temperature monitored by the control computer.

\section{Gano Partial Rod Insertion Test at Power}

RSP 90-007-12 will be modified to measure the reactivity effect and power perturbation caused by a 50 vu insertion of double partial rod gangs while the reactor is operating below ISAL rather than at $60 \%$ of full power. As in the other two partial rod tests, the full rod insertion will be the same in each gang. With this arrangement, no flux shape limits will restrict the performance of this test. The reactivity changes and power perturbations will be measured in the same manner as the single partial rod insertion at power. The revised expectation values for this test are presented in Figures $13-27$.

\section{Differential Full Rod Worth Measurement}

RSP 90-007-05 will be modified to include Figures 28 - 37. The expanded predictions cover the full rod positions for initial criticality that are within the limits described in the Technical Specifications. For the full rod differential measurements done at partial rod configurations other than for initial critical, the range of full rod positions were sufficient to cover the uncertainty associated with the estimated critical position $(\mathrm{ECP})^{1}$. 
WSRC-TR-91-043, Addendum 1

Page 4 of 42

October 21, 1991

\section{Calculation Method}

The details of the GLASS and GRIMHX calculations performed to establish the acceptance criteria and expectation values for these control rod worth measurements are explained in WSRC-TR-91-42-044 3. All of the cross sections used in this addendum were generated for the calculations performed in the referenced report. The GRIMHX geometric model is also the same. The analyses for this addendum were simplified since all the full rods were at the same insertion in each gang which was not the case in some earlier analyses.

For the single partial rod insertions, GRIMHX calculations were performed for cases with full rods between $500 \mathrm{vu}$ and 3300 vu at 50 vu increments. These were the base case calculations where double partial rods were located at 800 vu. Another set of GRIMHX calculations were performed where a single partial rod (either weak or strong) was inserted to $950 \mathrm{vu}$ in one of the control clusters 1,36 , or 52. These were also performed with full rods between $500 \mathrm{vu}$ and $3300 \mathrm{vu}$ at 50 vu increments. The difference in calculated keff between the inserted partial rod case and base case for the same full rod insertion was the reactivity worth of the inserted partial rod.

Similar calculations were performed for the gang partial rod insertion cases, but the full rod range was between 500 vu and $2500 \mathrm{vu}$. The maximum full rod insertion of 2500 vu was estimated as the full rod position at $280 \mathrm{MW}$ equilibrium power in a reactor that initially became critical at 3300 vu. GRIMHX calculations were performed with double partial rods at $850 \mathrm{vu}$ in one gang and the other two gangs at $800 \mathrm{vu}$. Again, the difference in calculated keff between the insertion case and the base case is the reactivity worth of the inserted partial rod gang.

Calculations for the differential rod worth measurements with the double partial rods at 800 vu were made to cover the full rod positions from 1100 vu to $1700 \mathrm{vu}$ and $2700 \mathrm{vu}$ to $3250 \mathrm{vu}$. The earlier calculations only covered the full rod range from $1700 \mathrm{vu}$ to $2700 \mathrm{vu}$. The method of calculation for the differential measurements is the same as that described in WSRC-TR-91-42-044. 
WSRC-TR-91-043, Addendum 1

Page 5 of 42

October 21, 1991

\section{REFERENCES}

1. Bond, R. A., Predictions and Acceptance Criteria for $K$ Reacter Startur and Power Ascension (UL, WSRC-TR-91-42-043, June 1991.

2. Savannah River Situ Production Reactor Technical Specifications (U), WSRC-TS-10003, September 3, 1991.

3. Bond, R. A., Calculations for Centrol Red Worth Measurements During $K$ Reactor Startur and Power_Ascension (U), WSRC-TR-91-42-044, June 1991. 


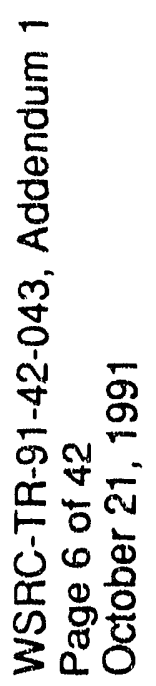

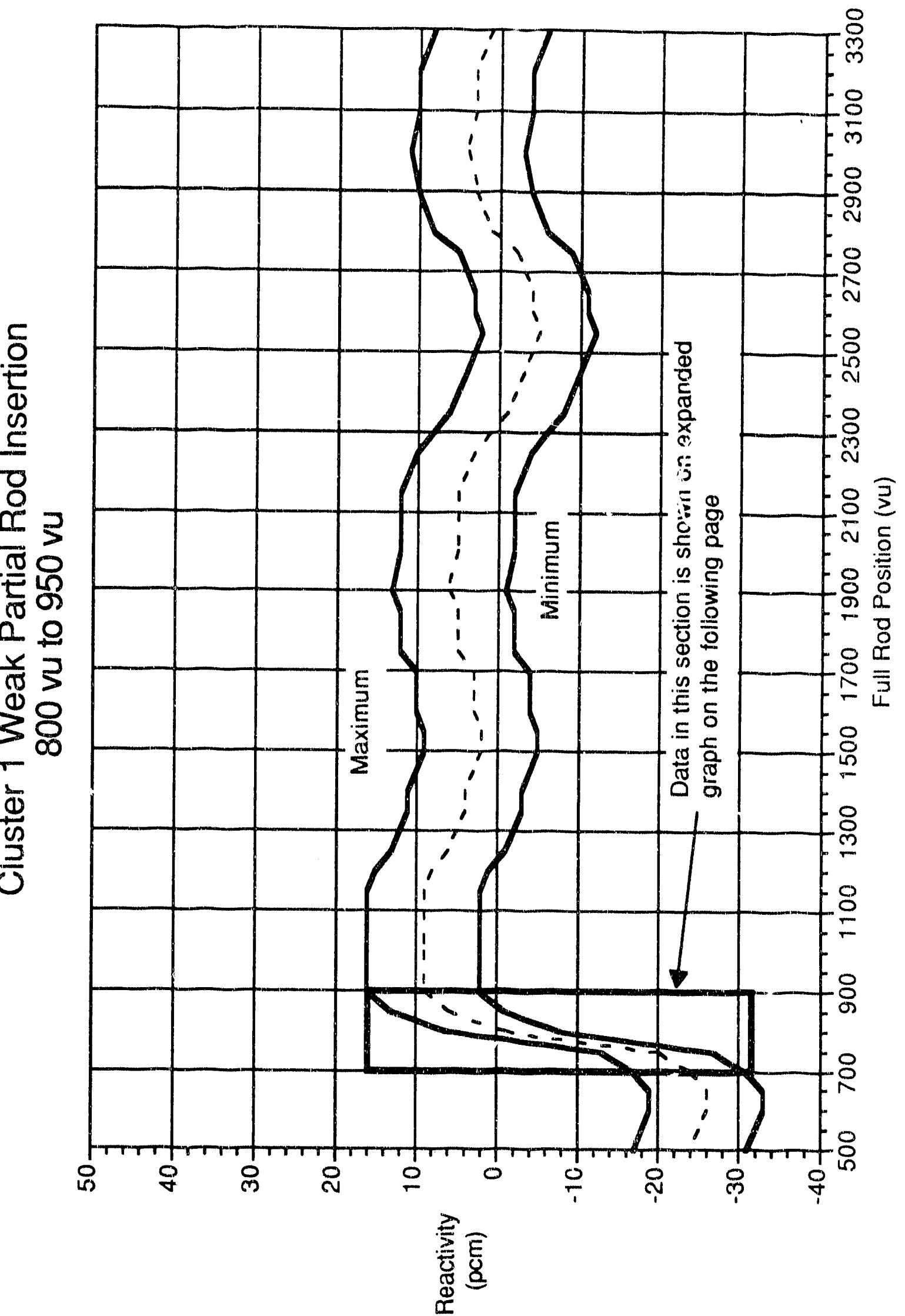




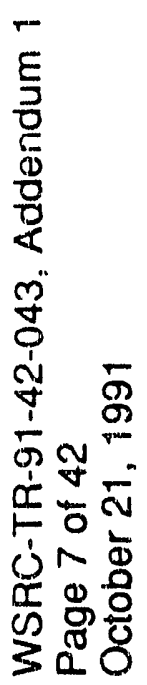

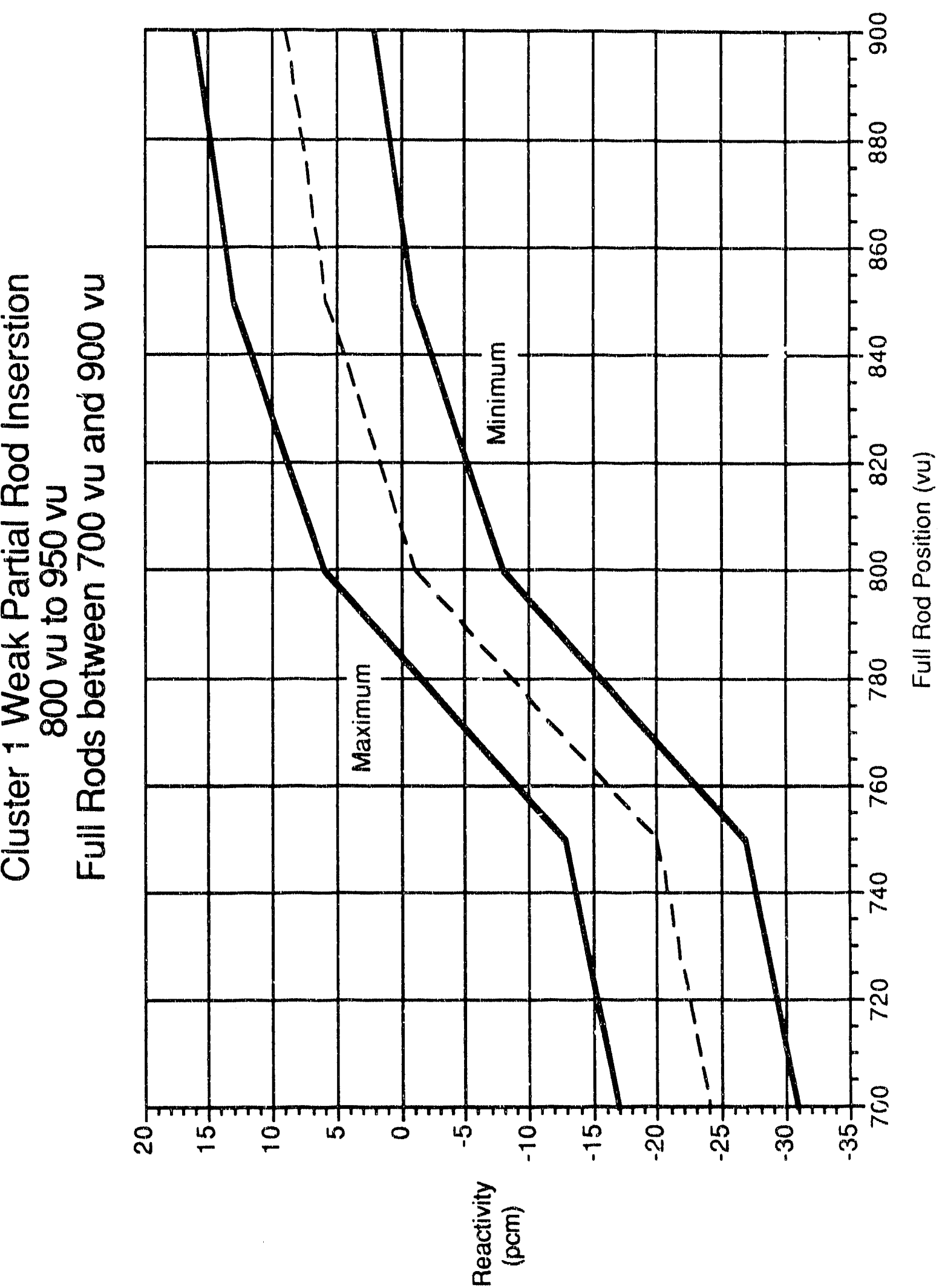



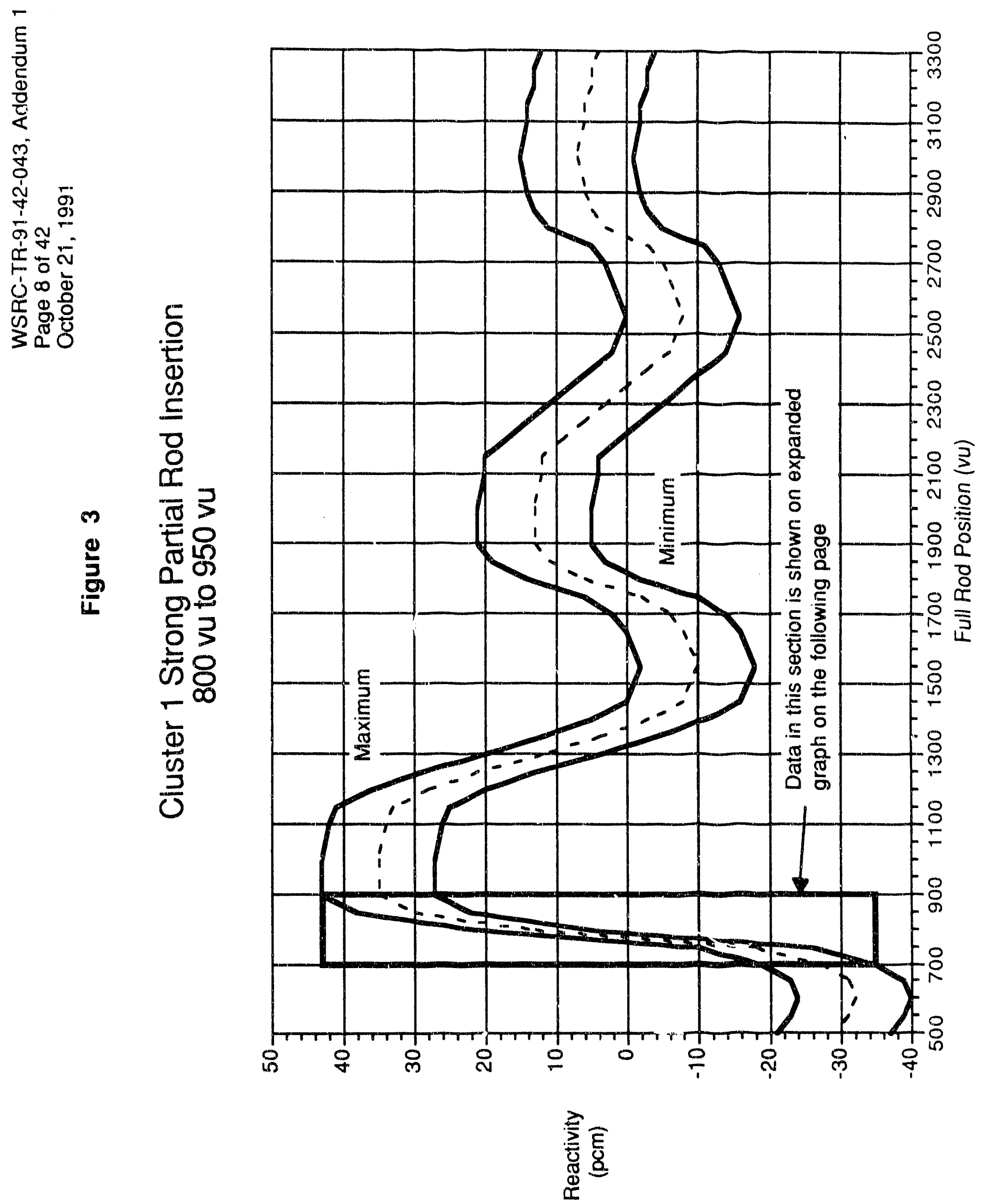


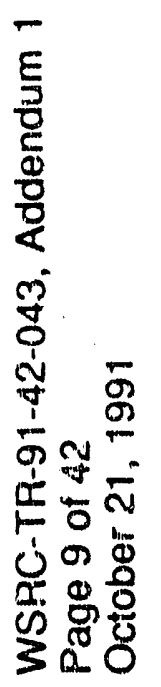

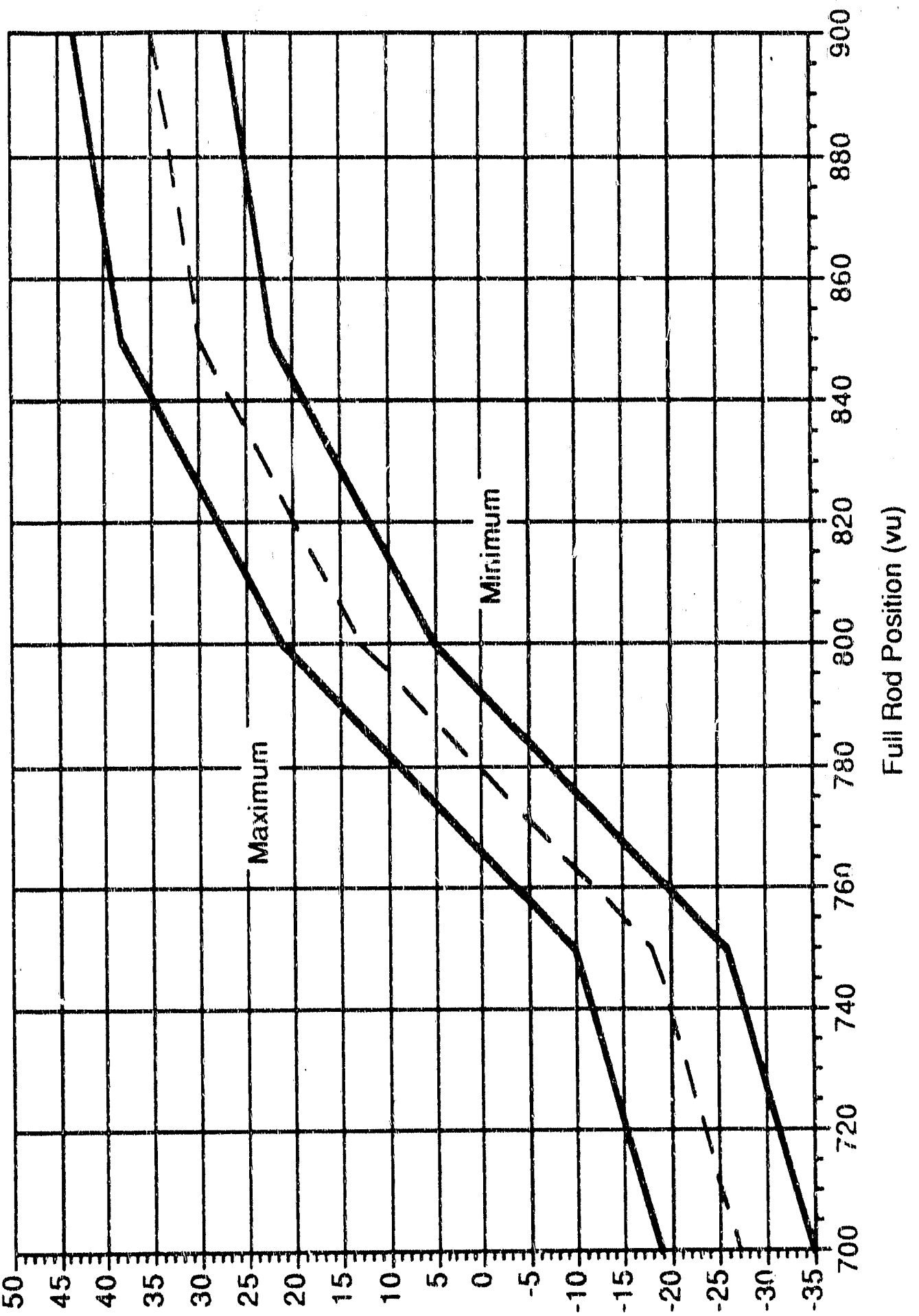

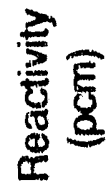




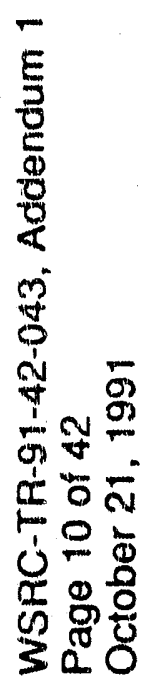

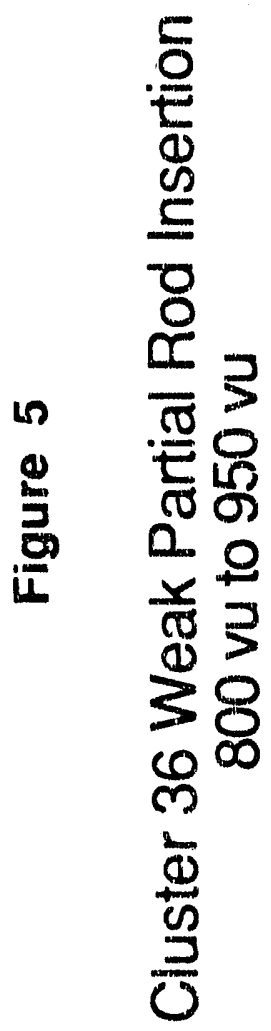

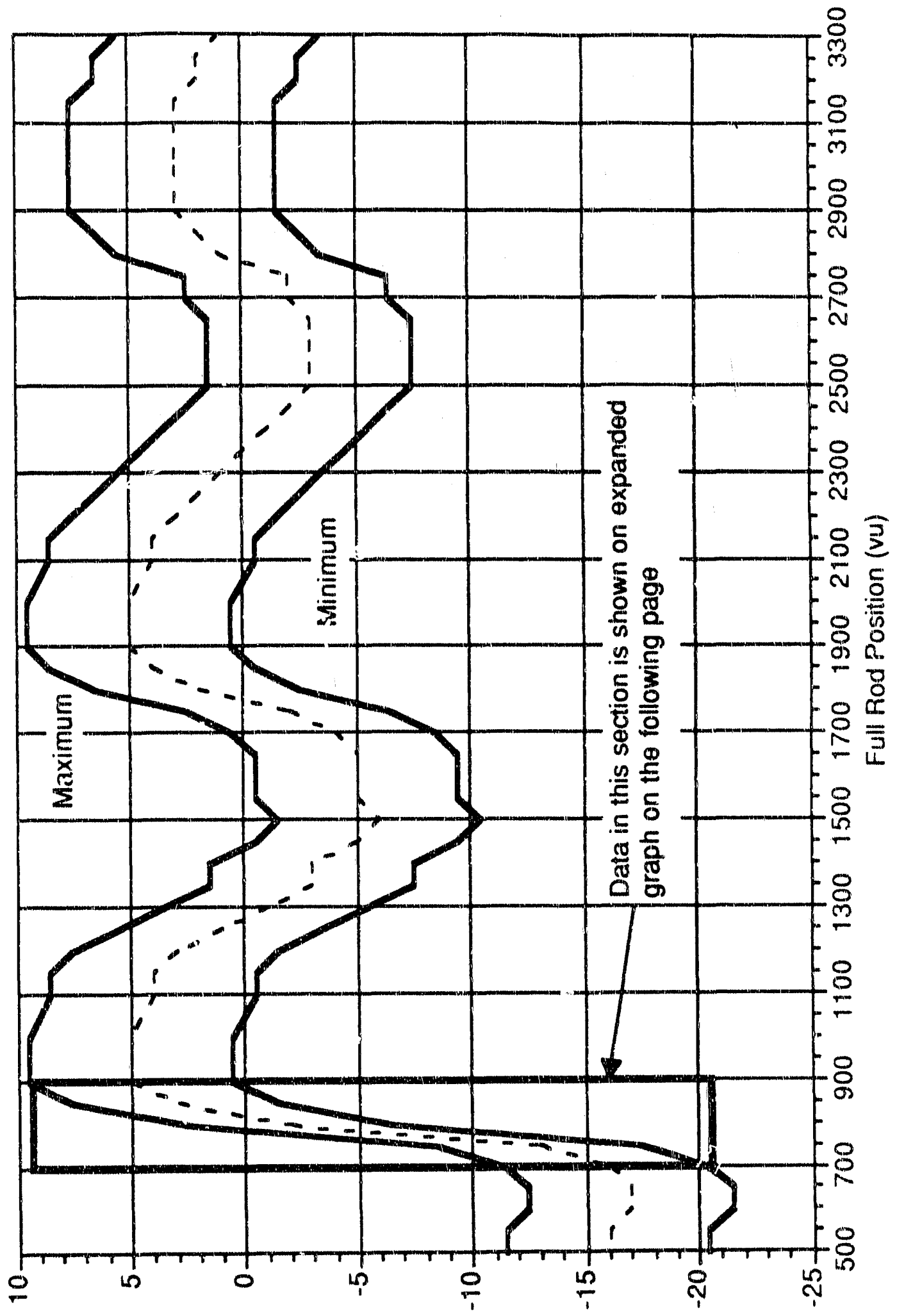

冚嘼 


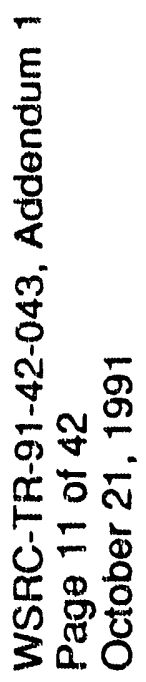

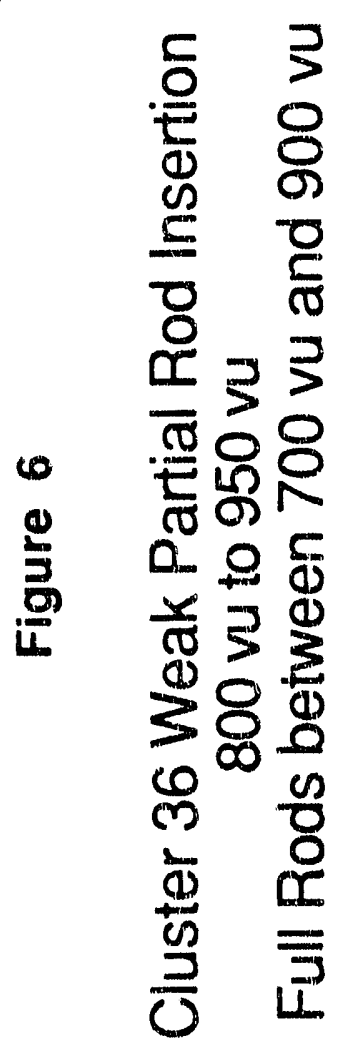

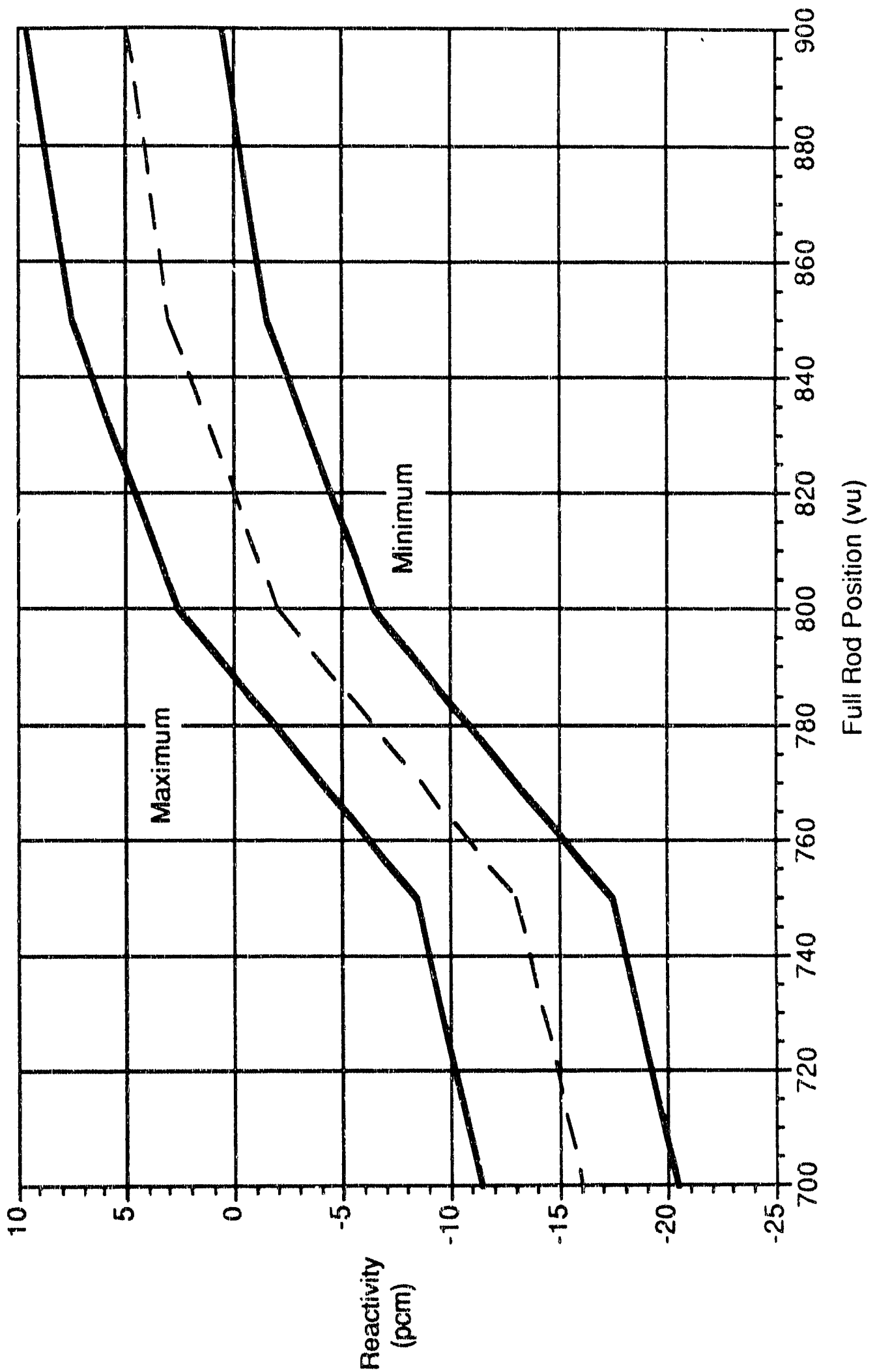




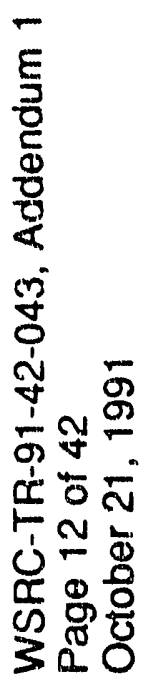

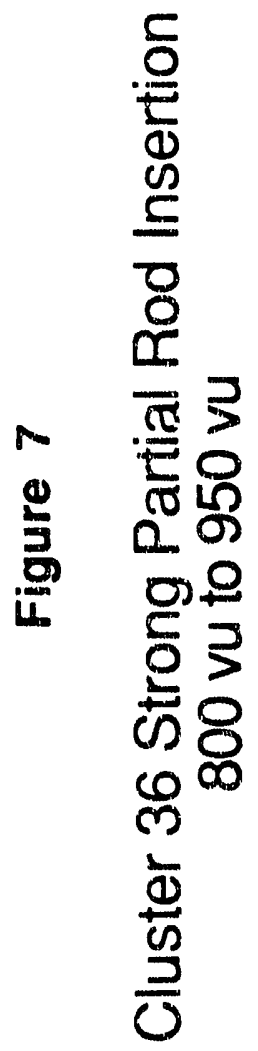

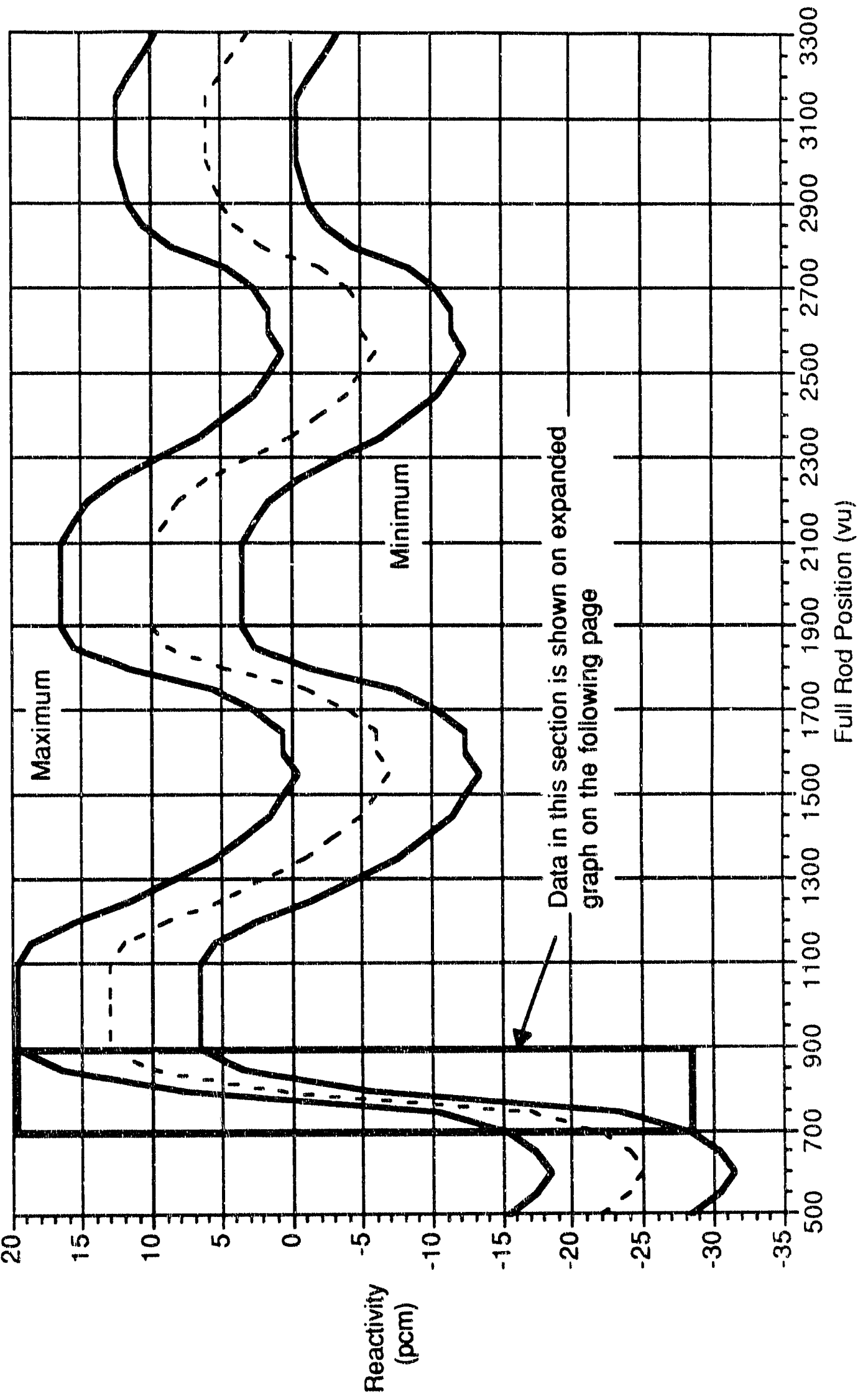



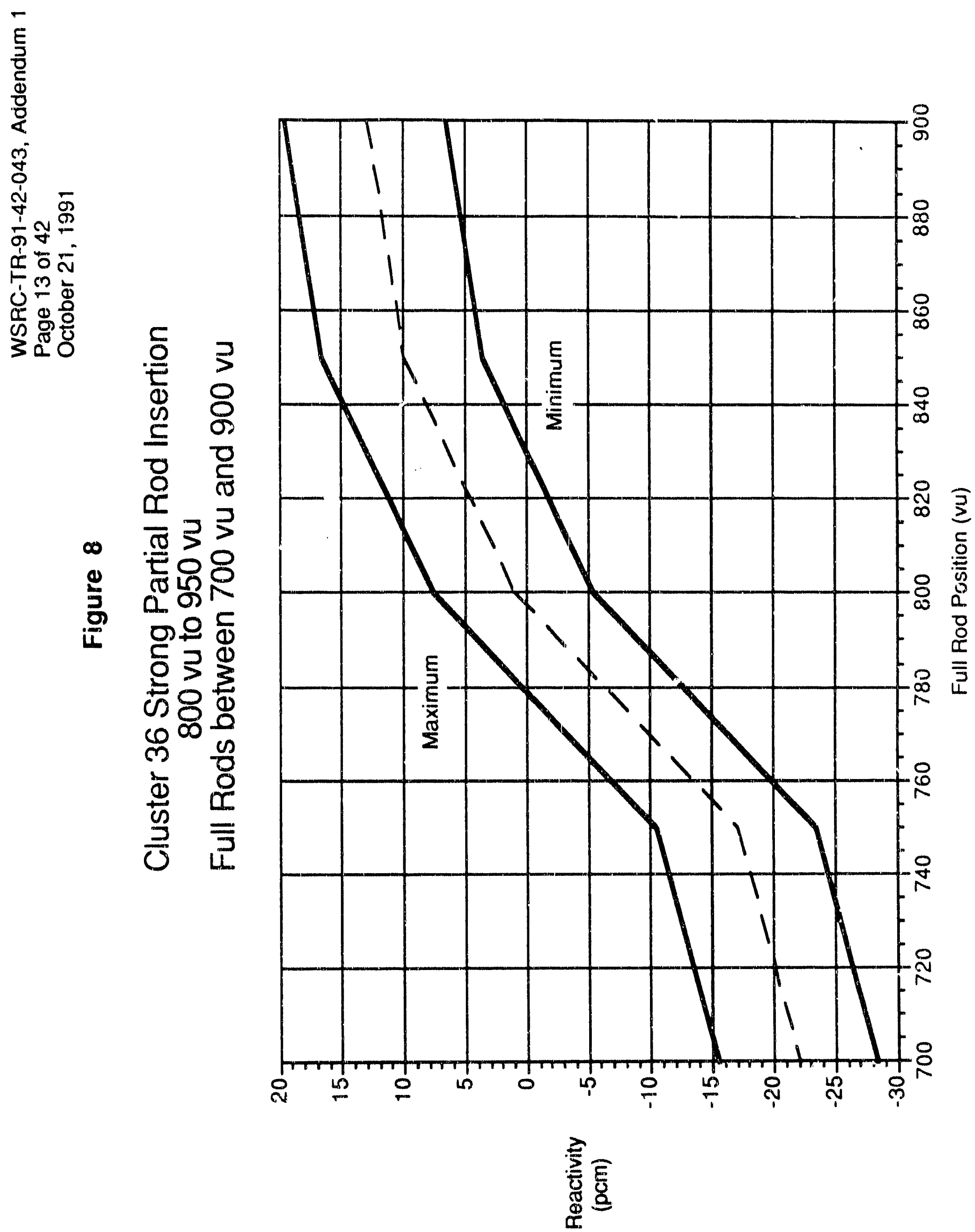


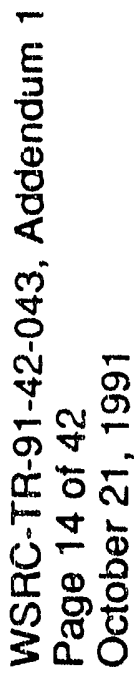
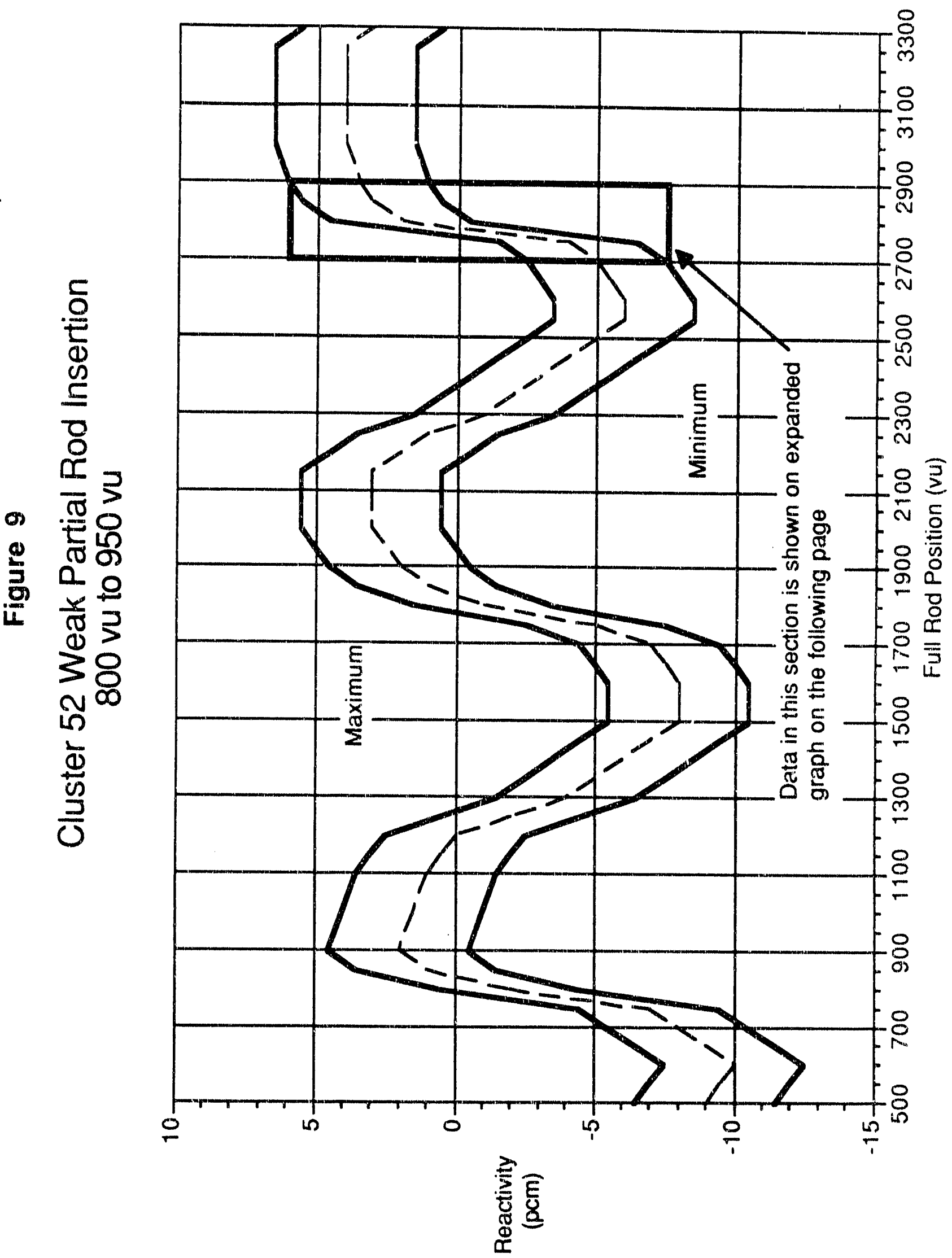


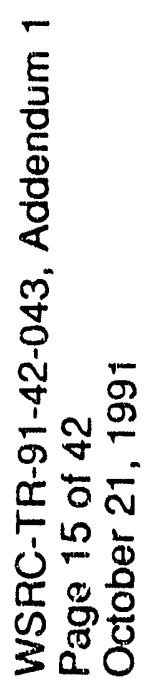

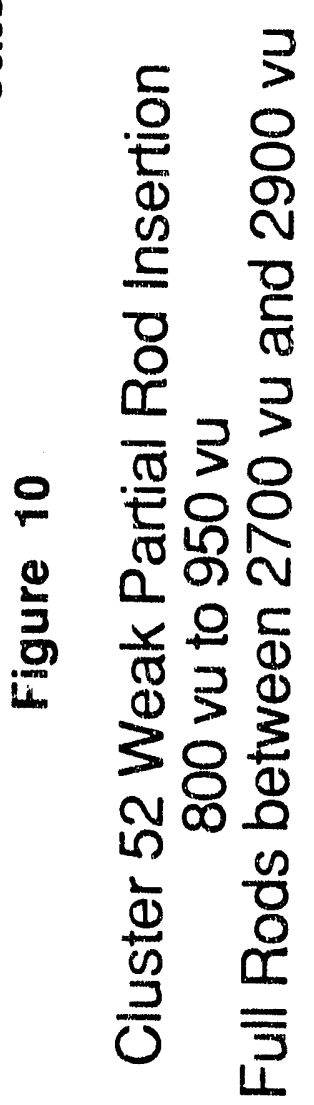

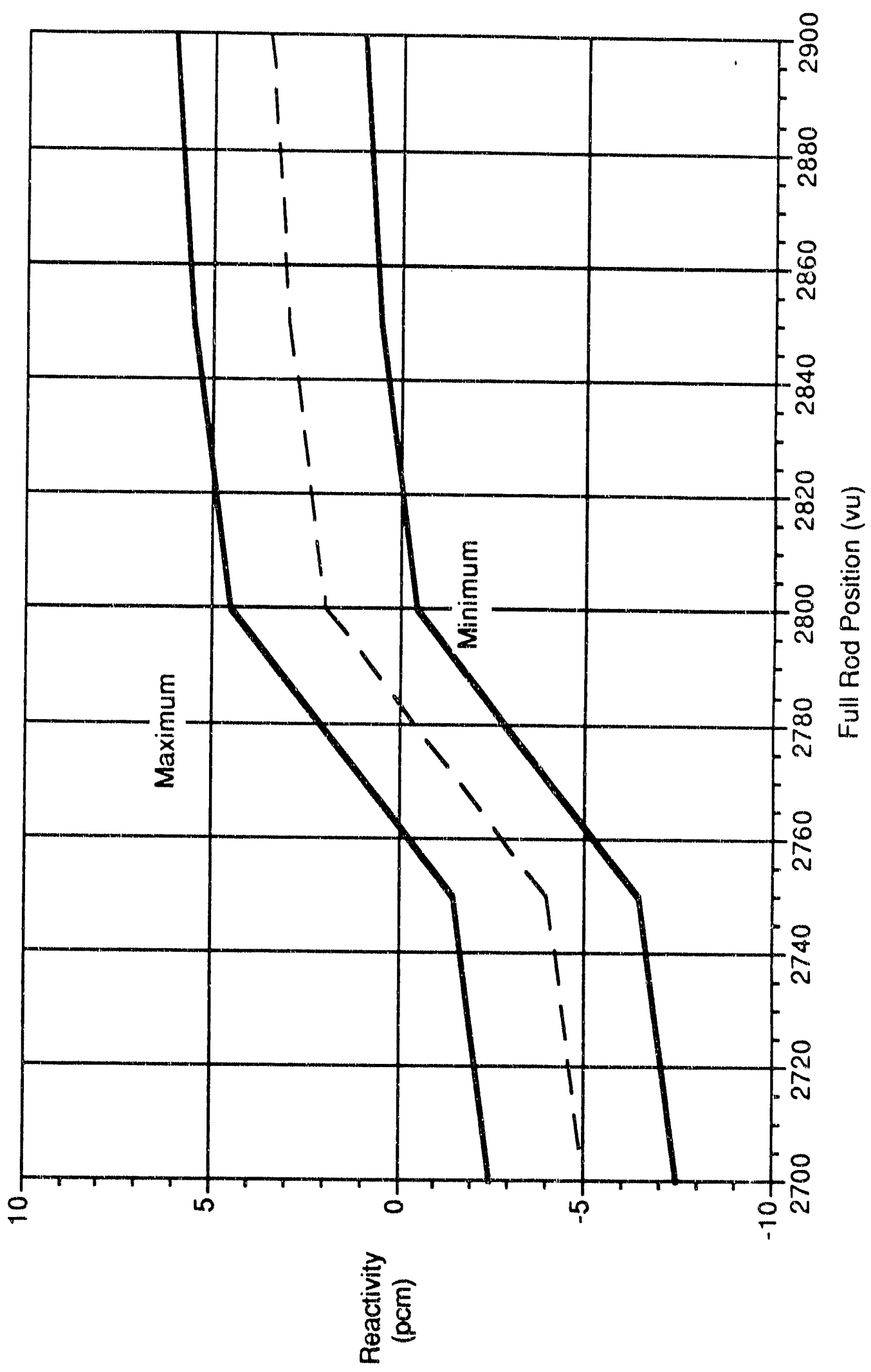



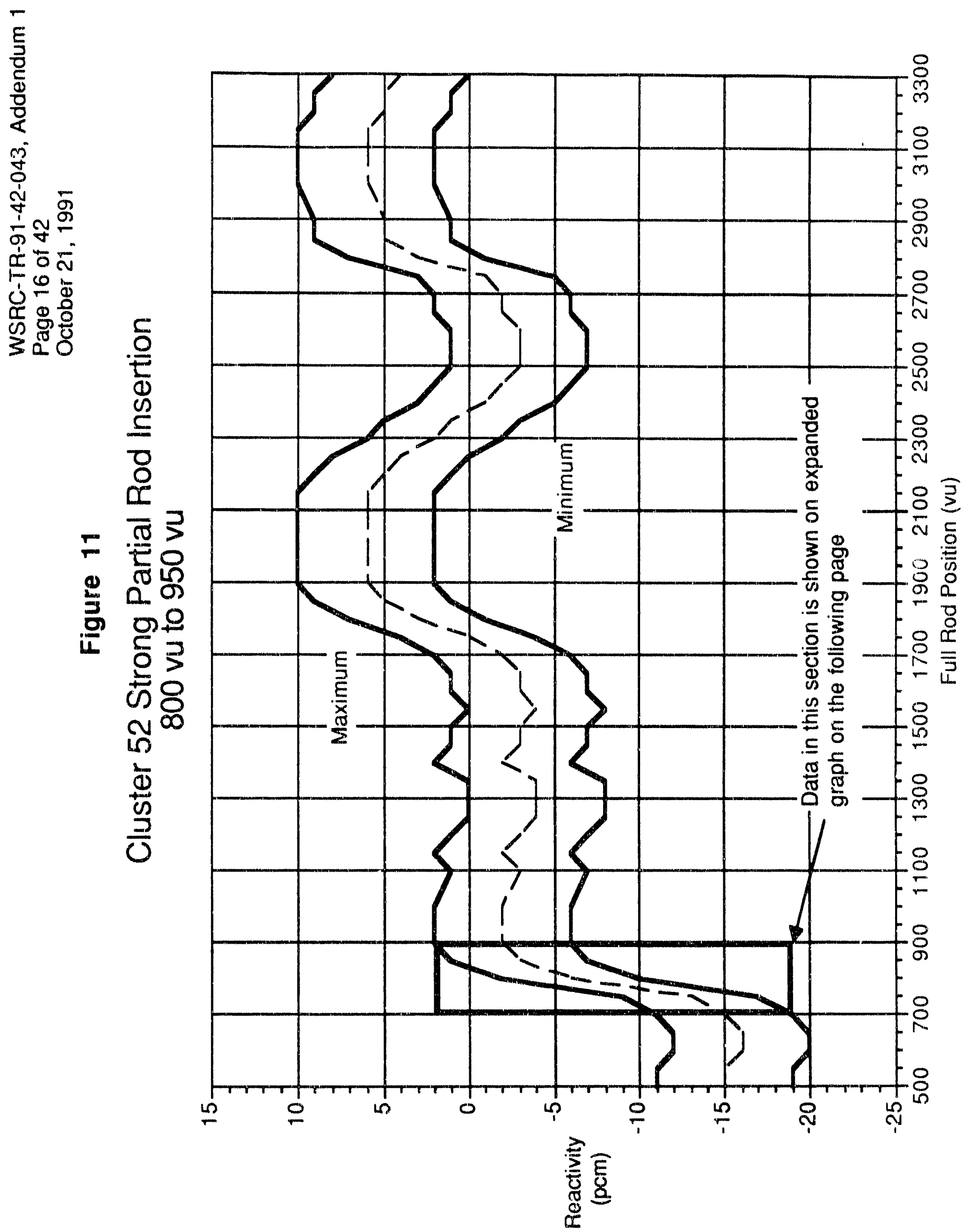


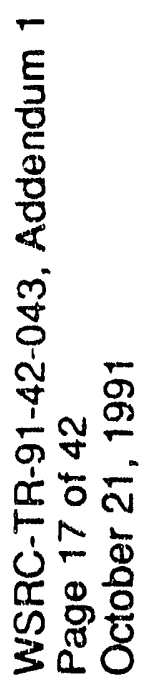

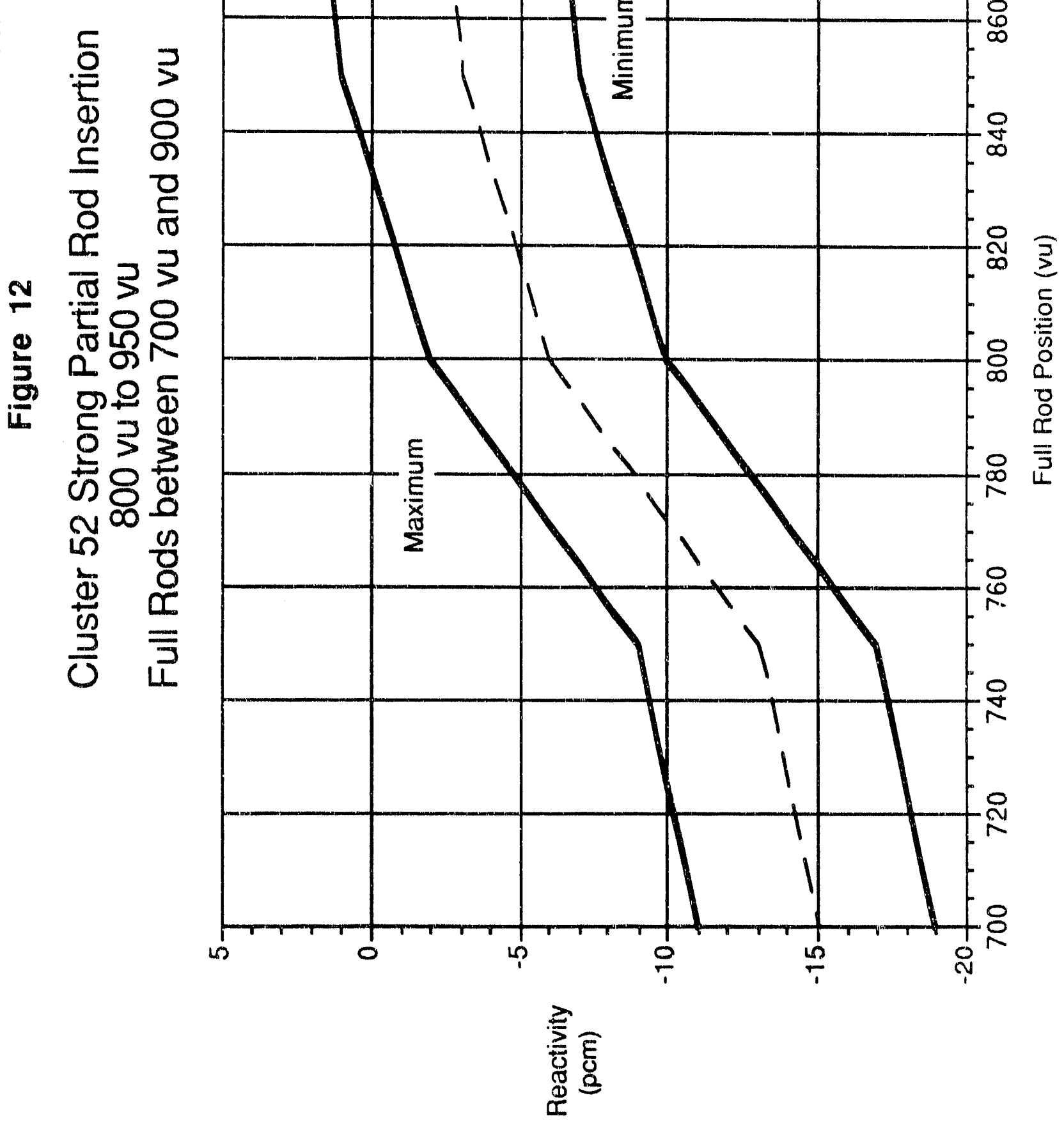




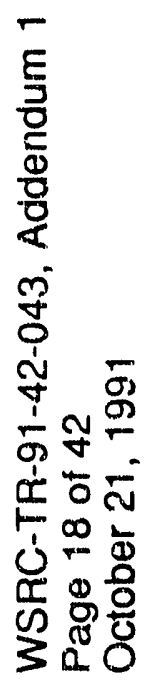

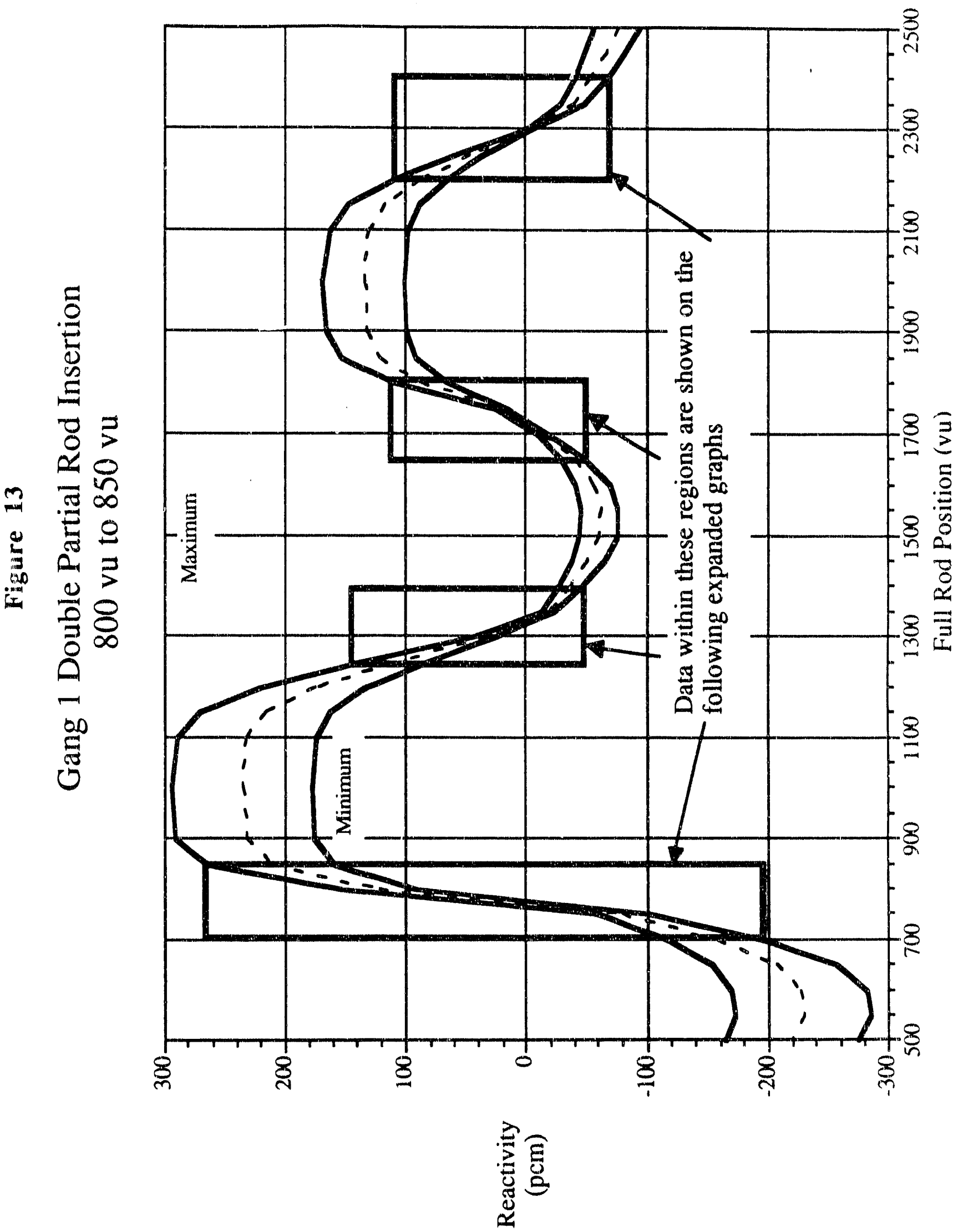




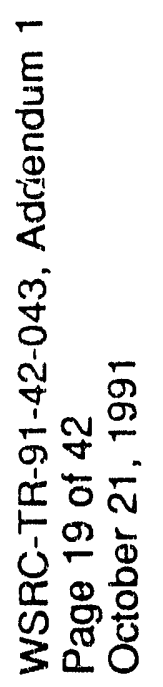

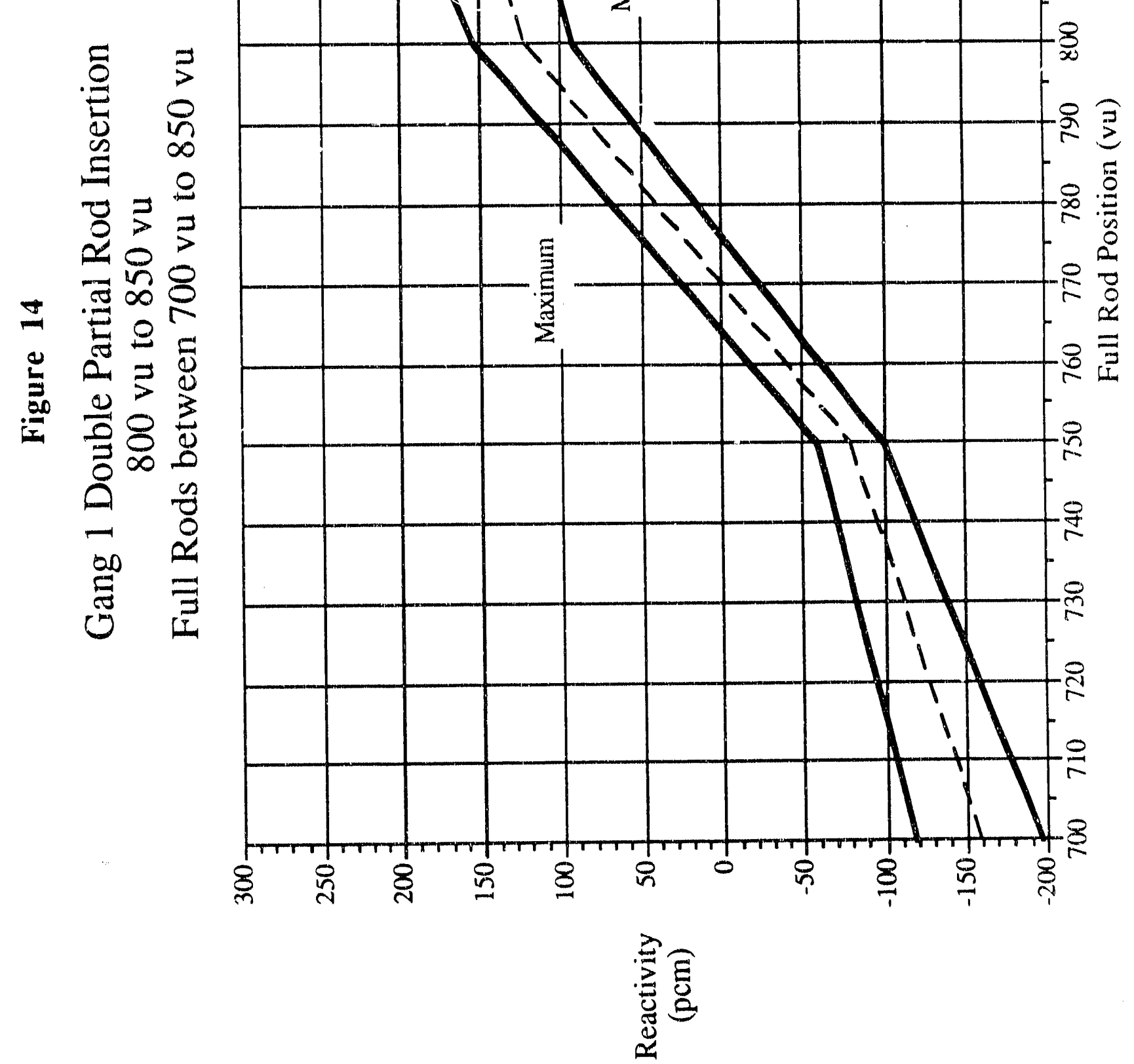




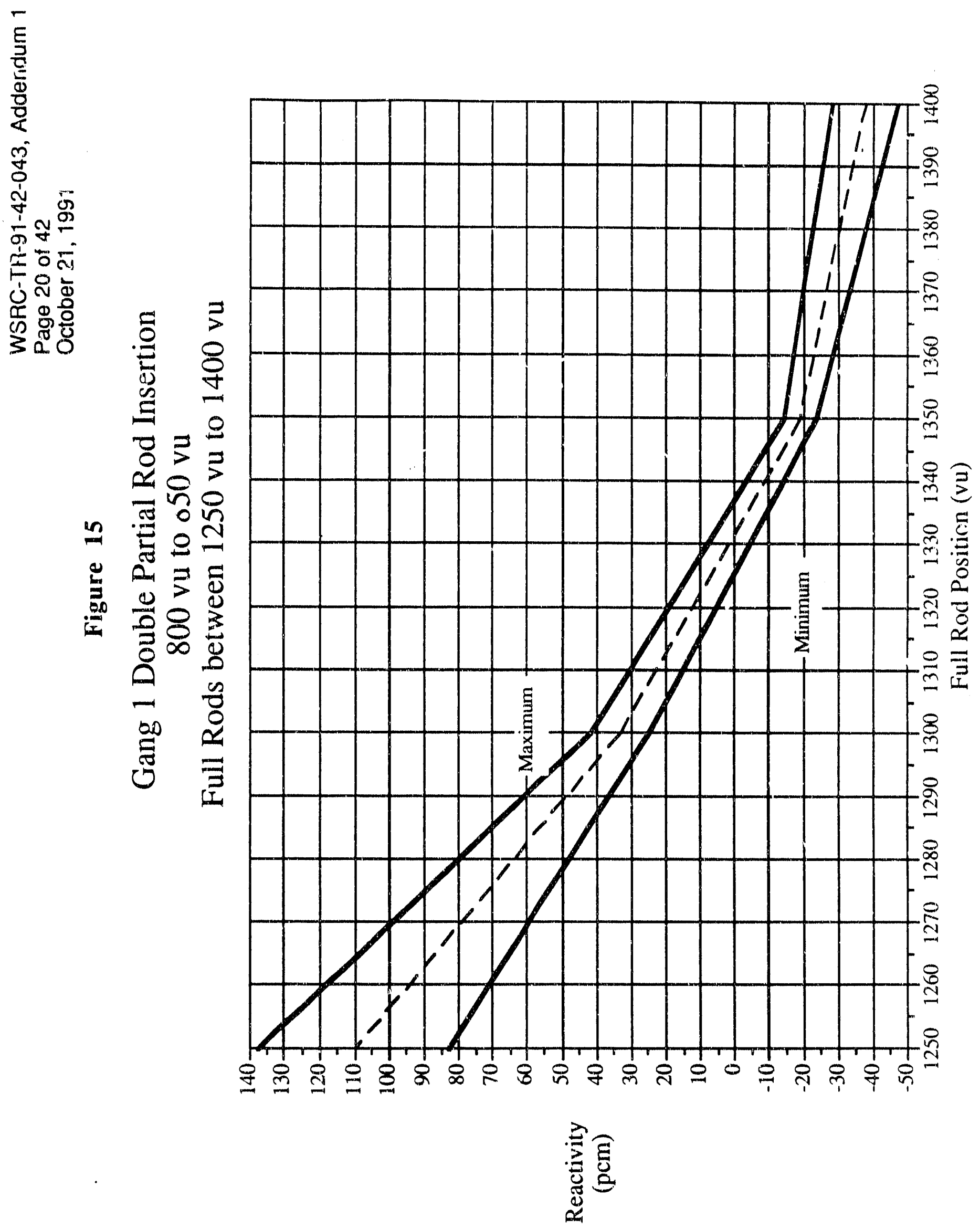



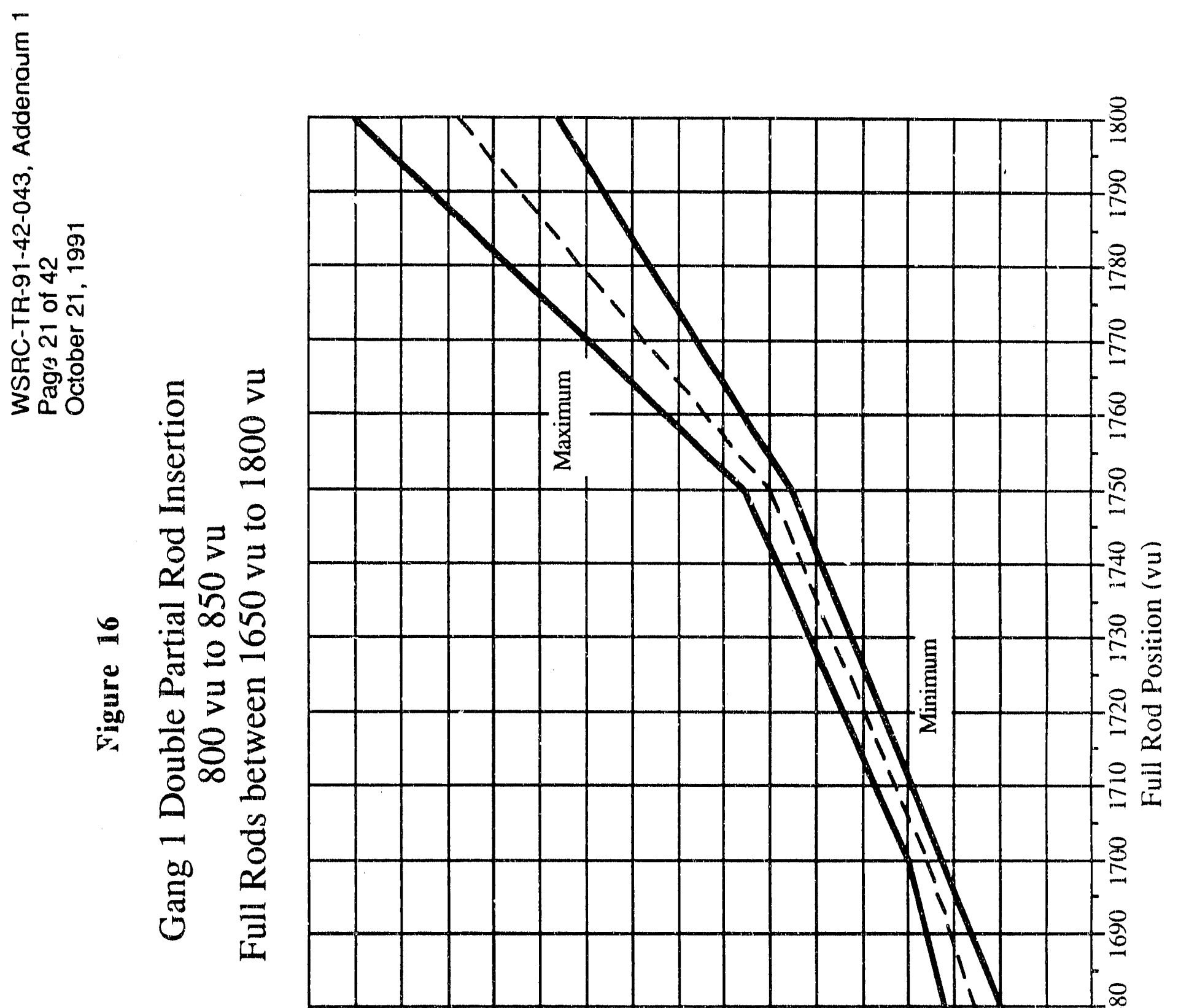

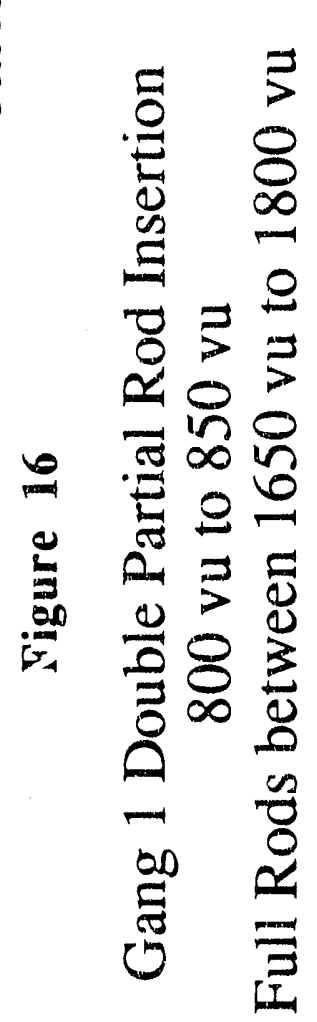

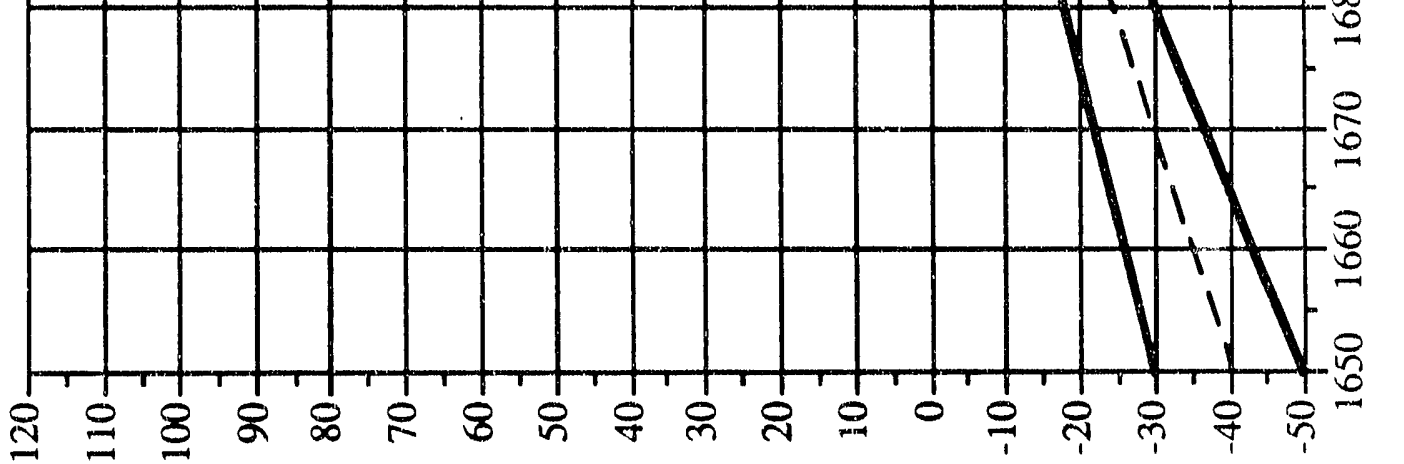

$\sum_{2}^{2}$
$\frac{2}{3}$
$\frac{1}{2}$ 


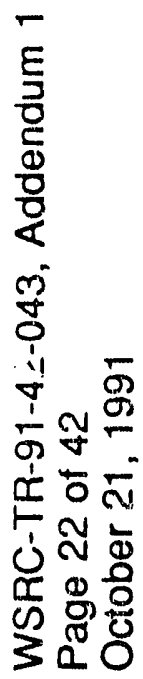

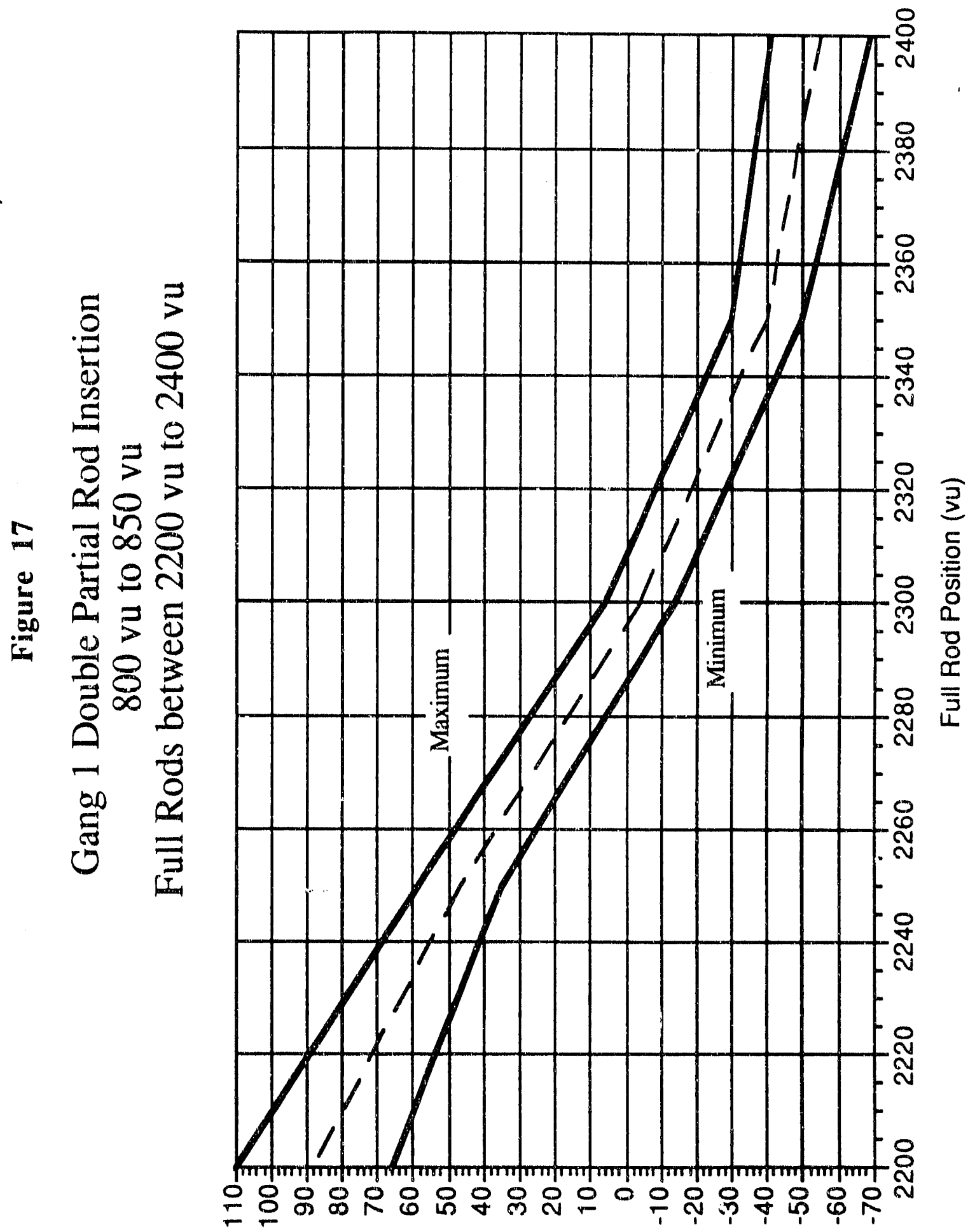

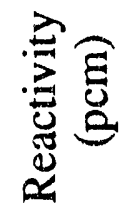




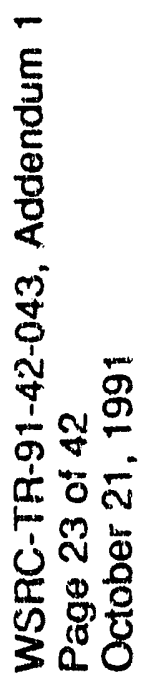

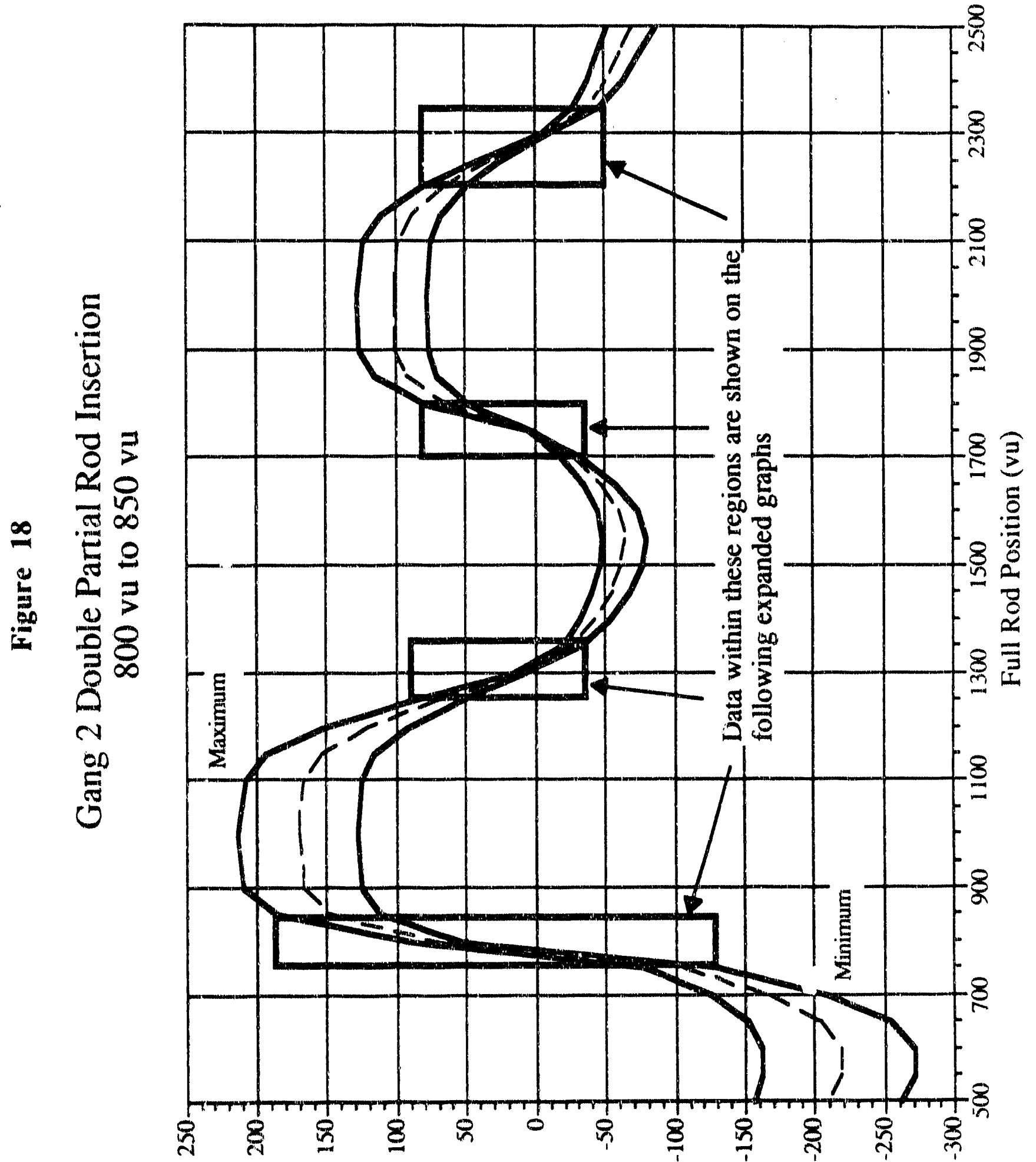

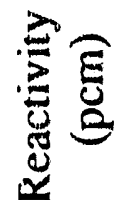




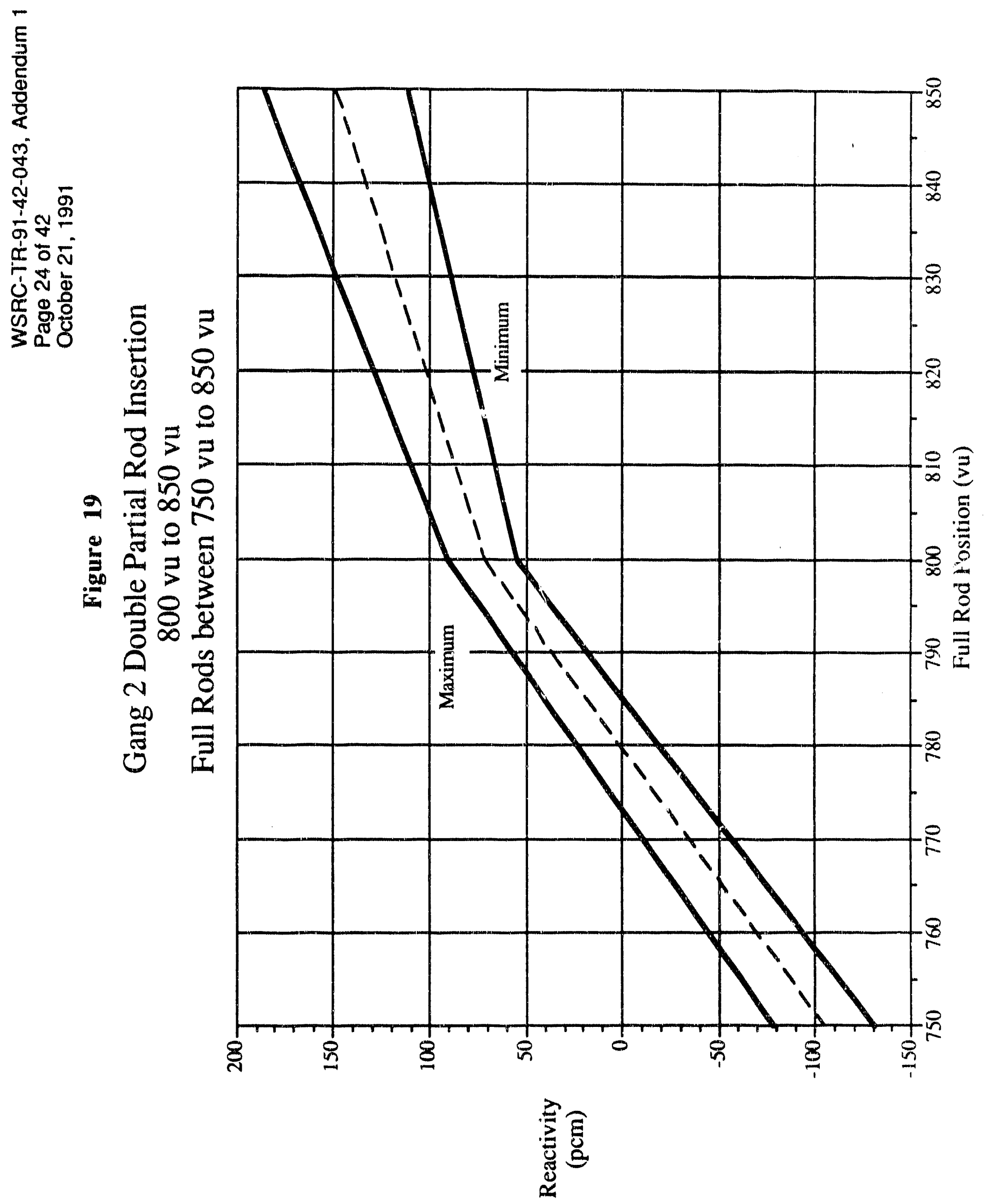



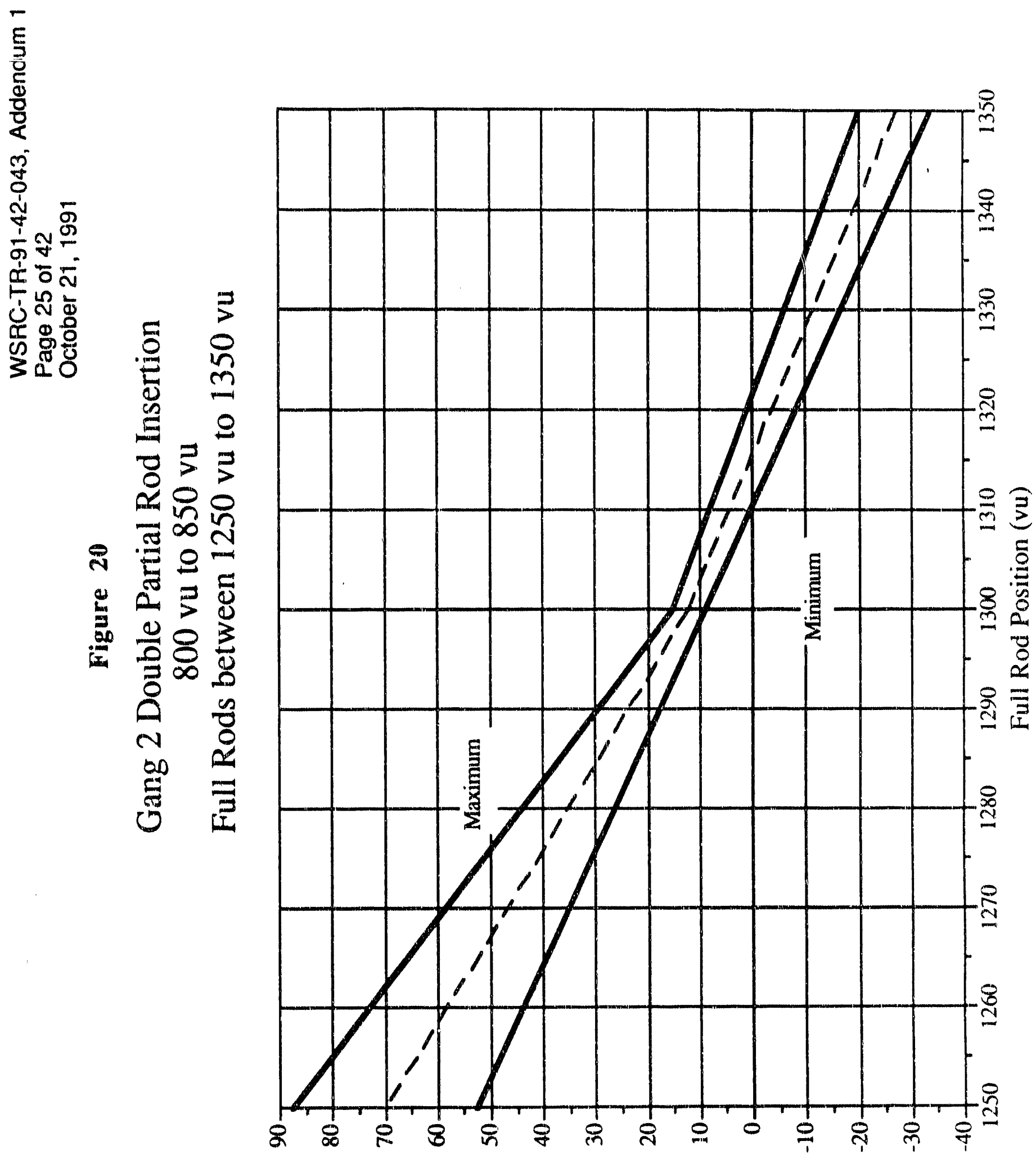

胥导 


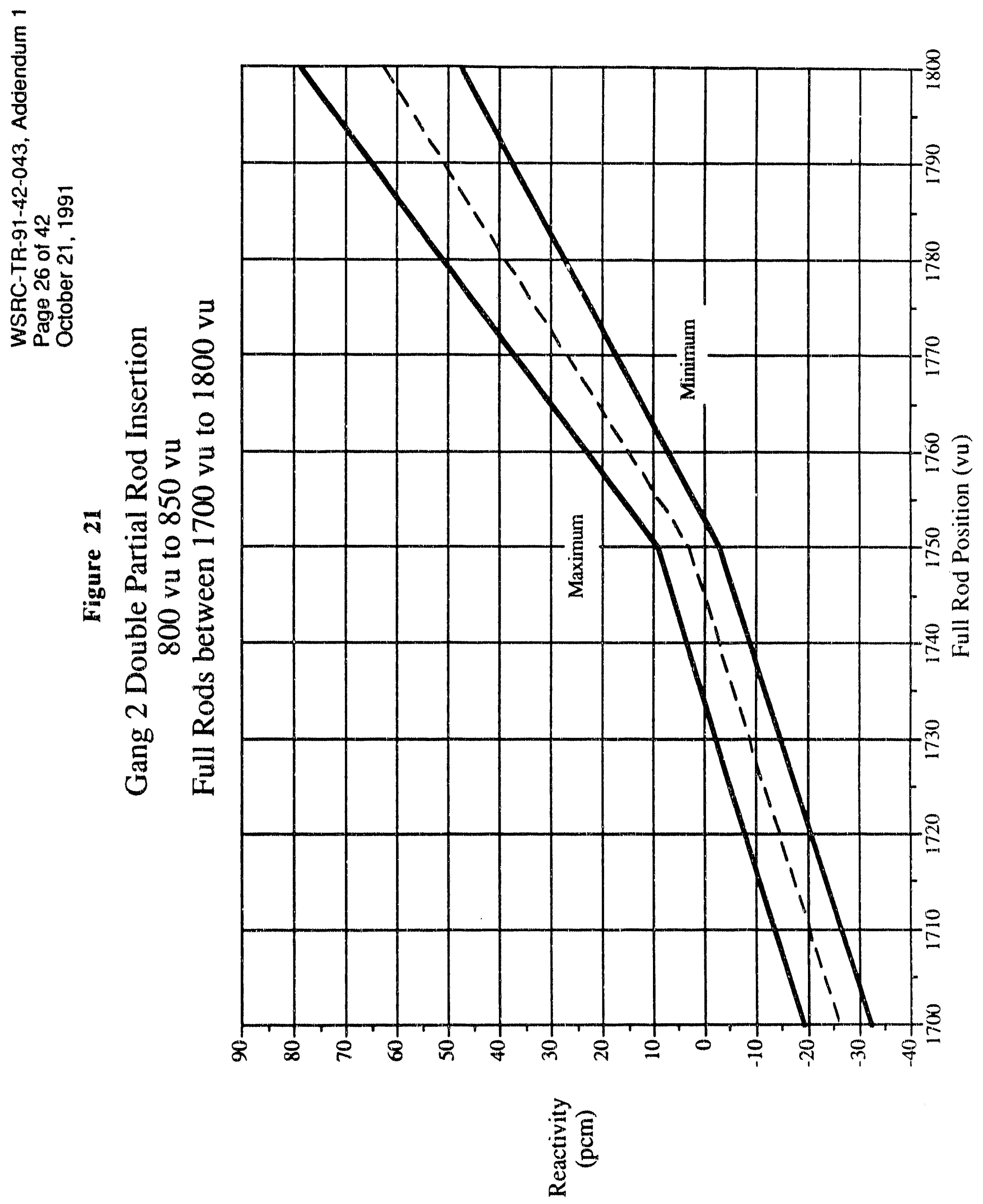




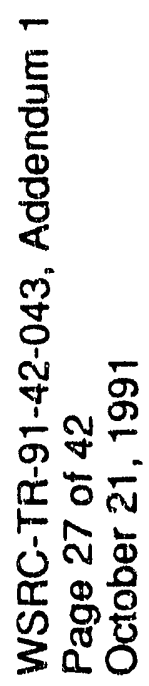

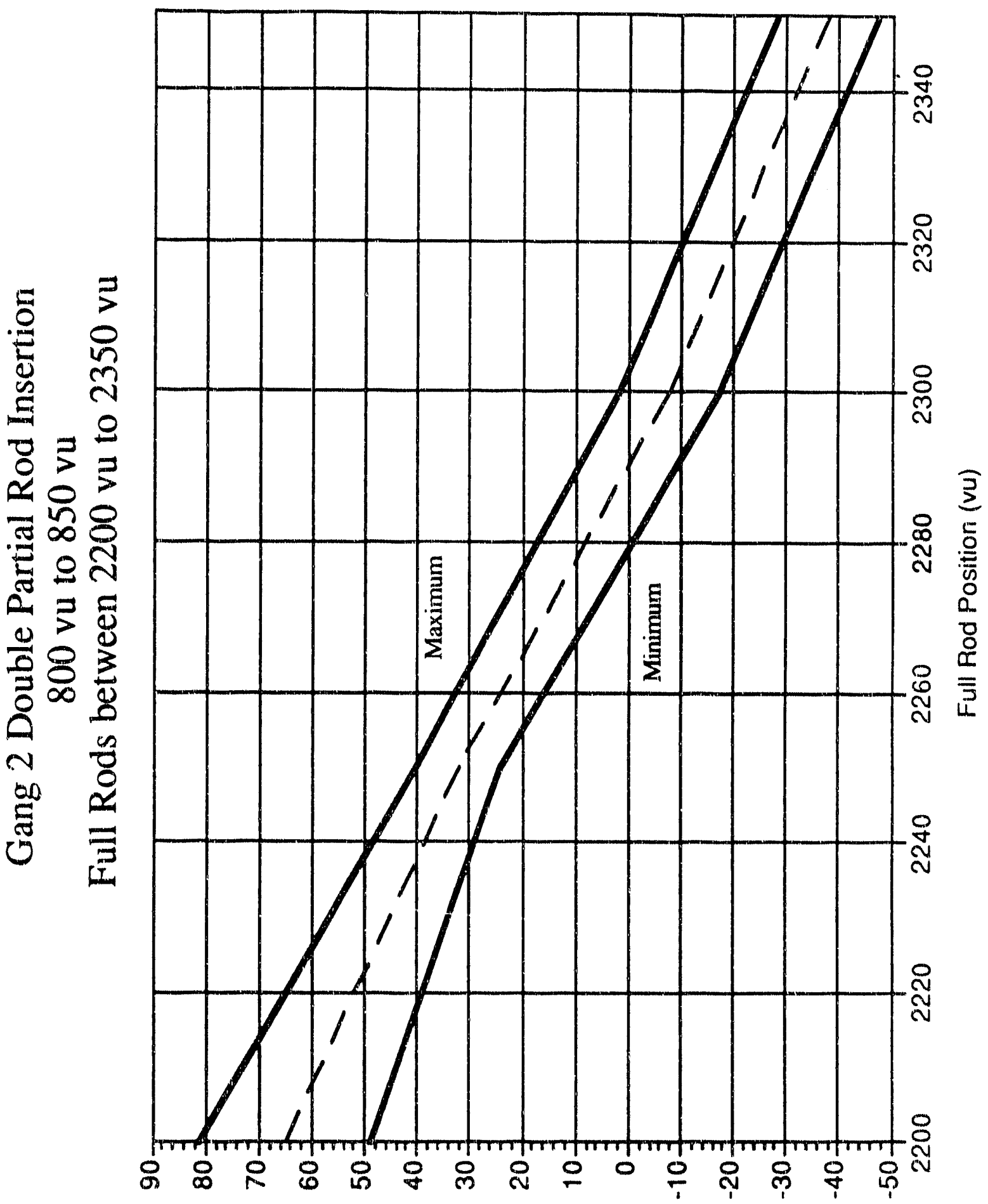

总点 


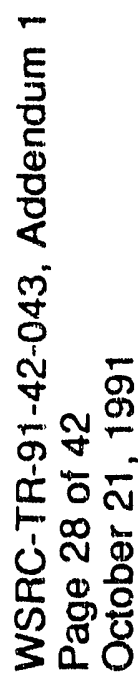

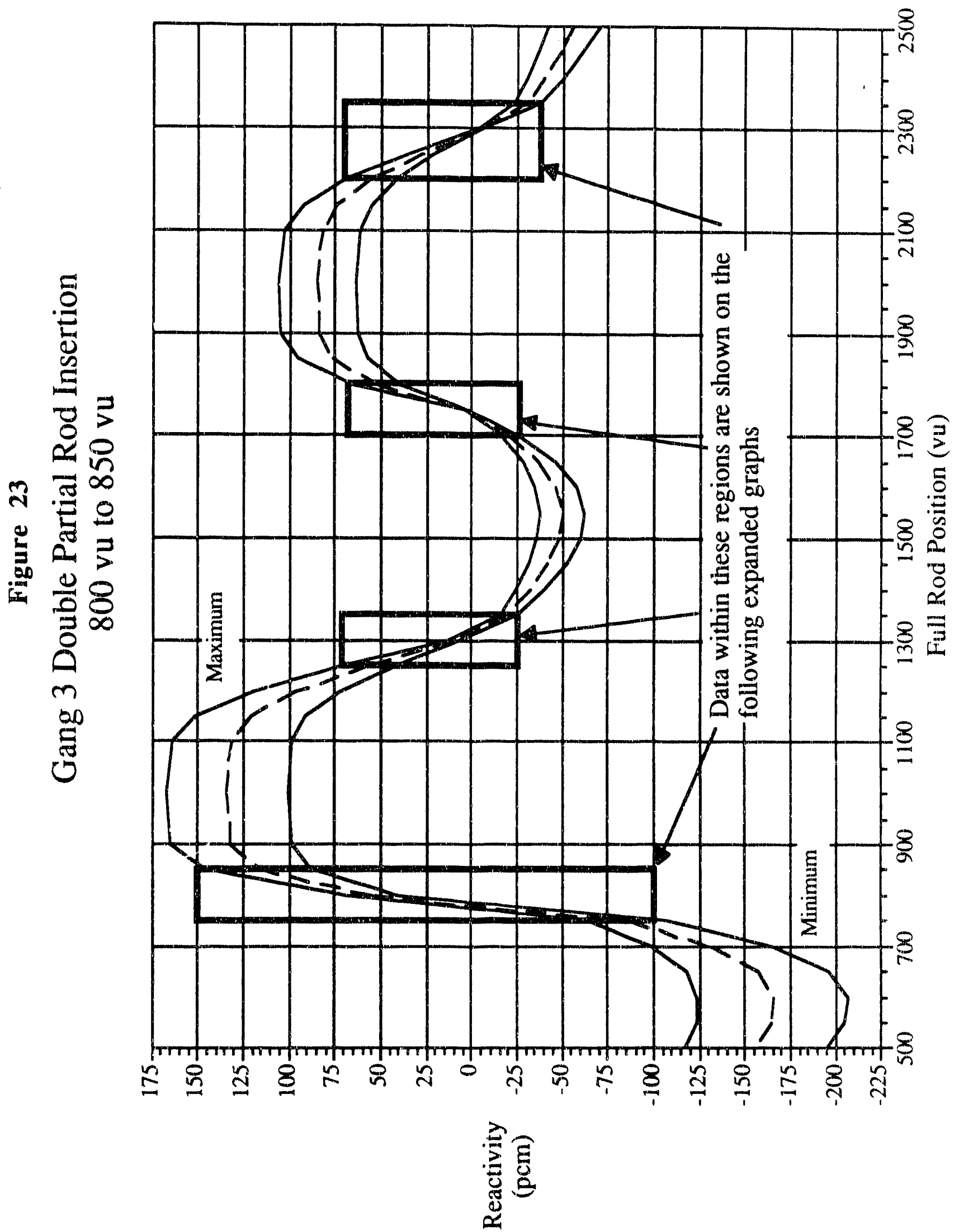




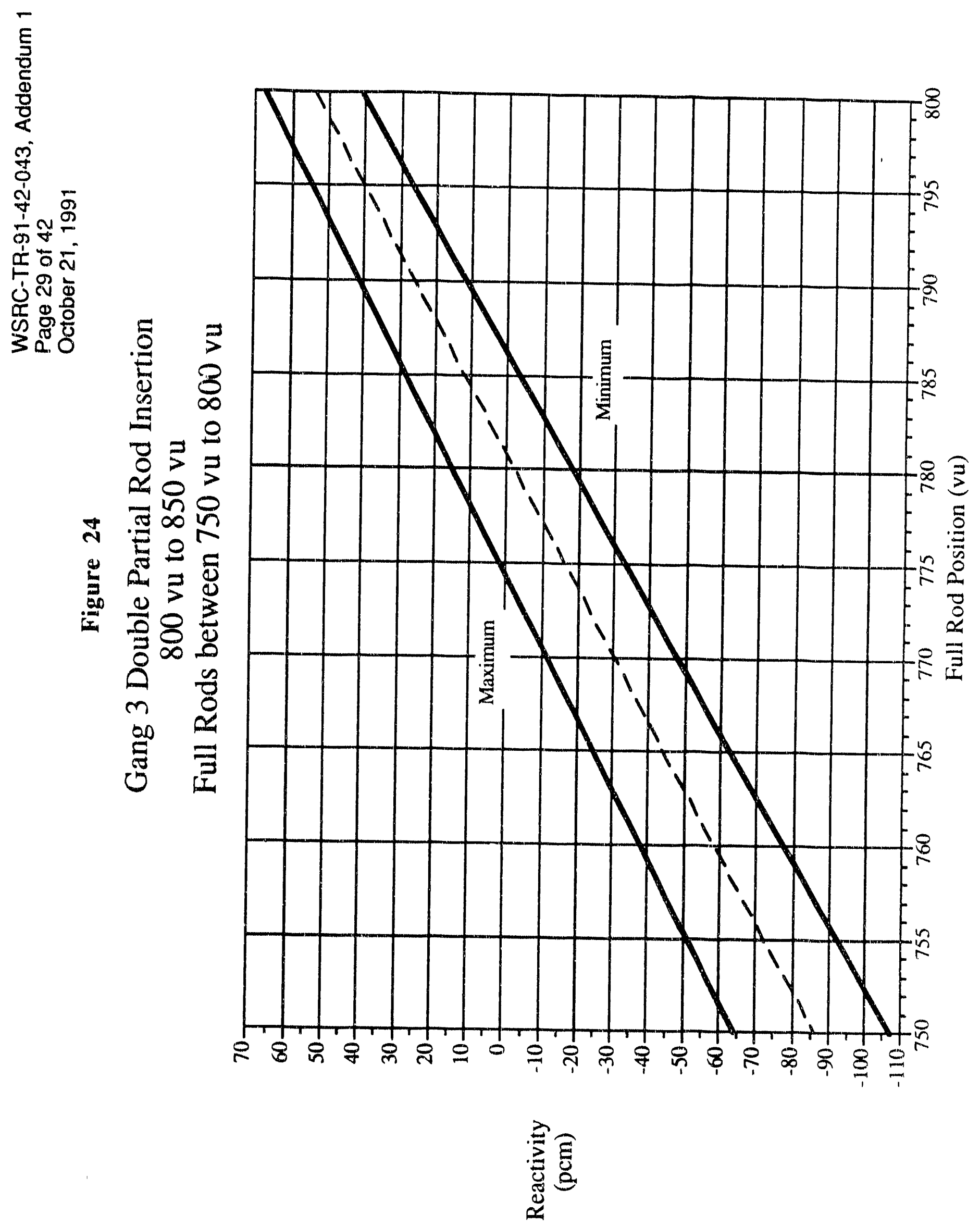




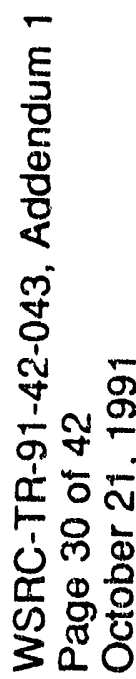
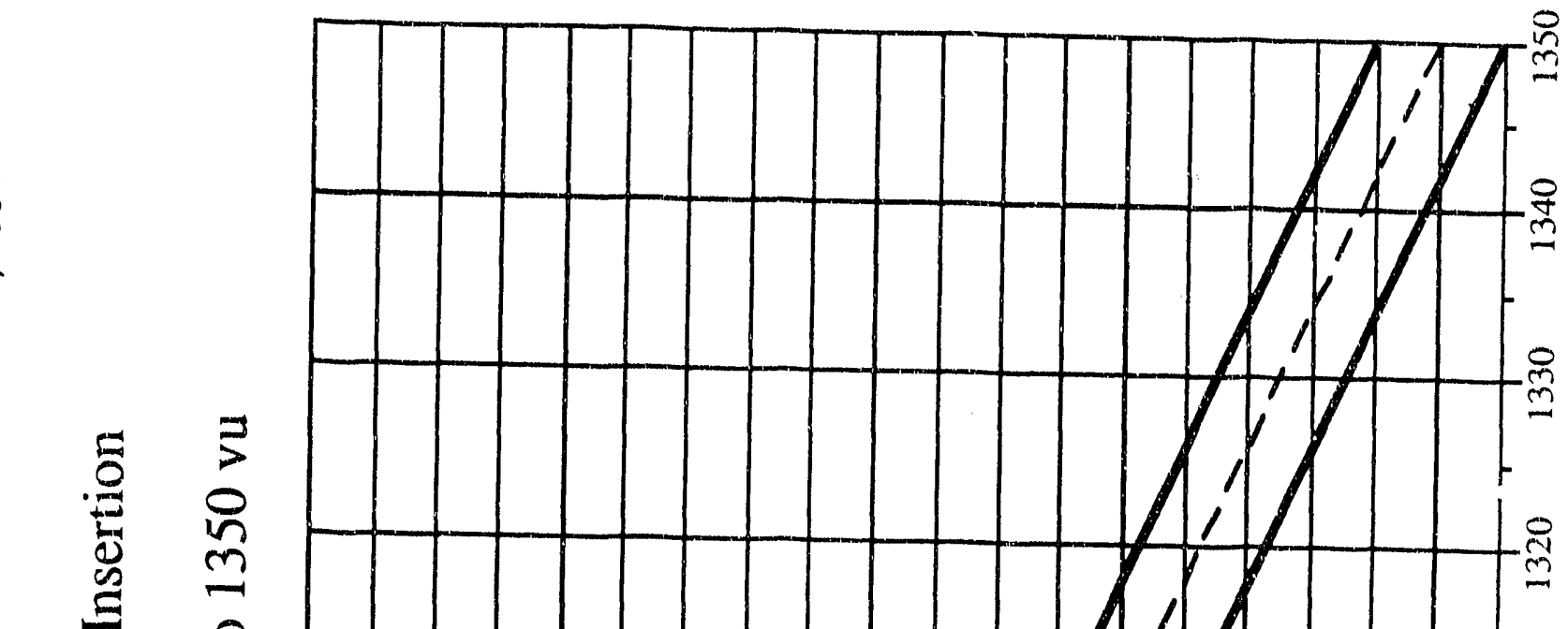

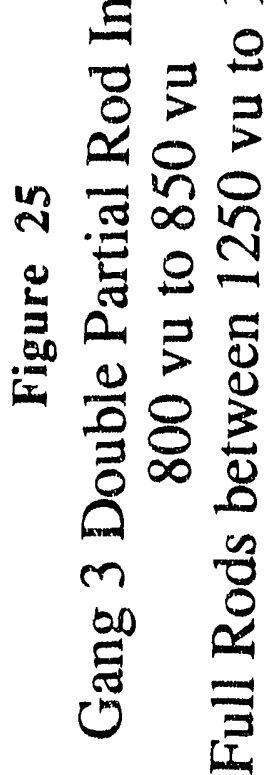




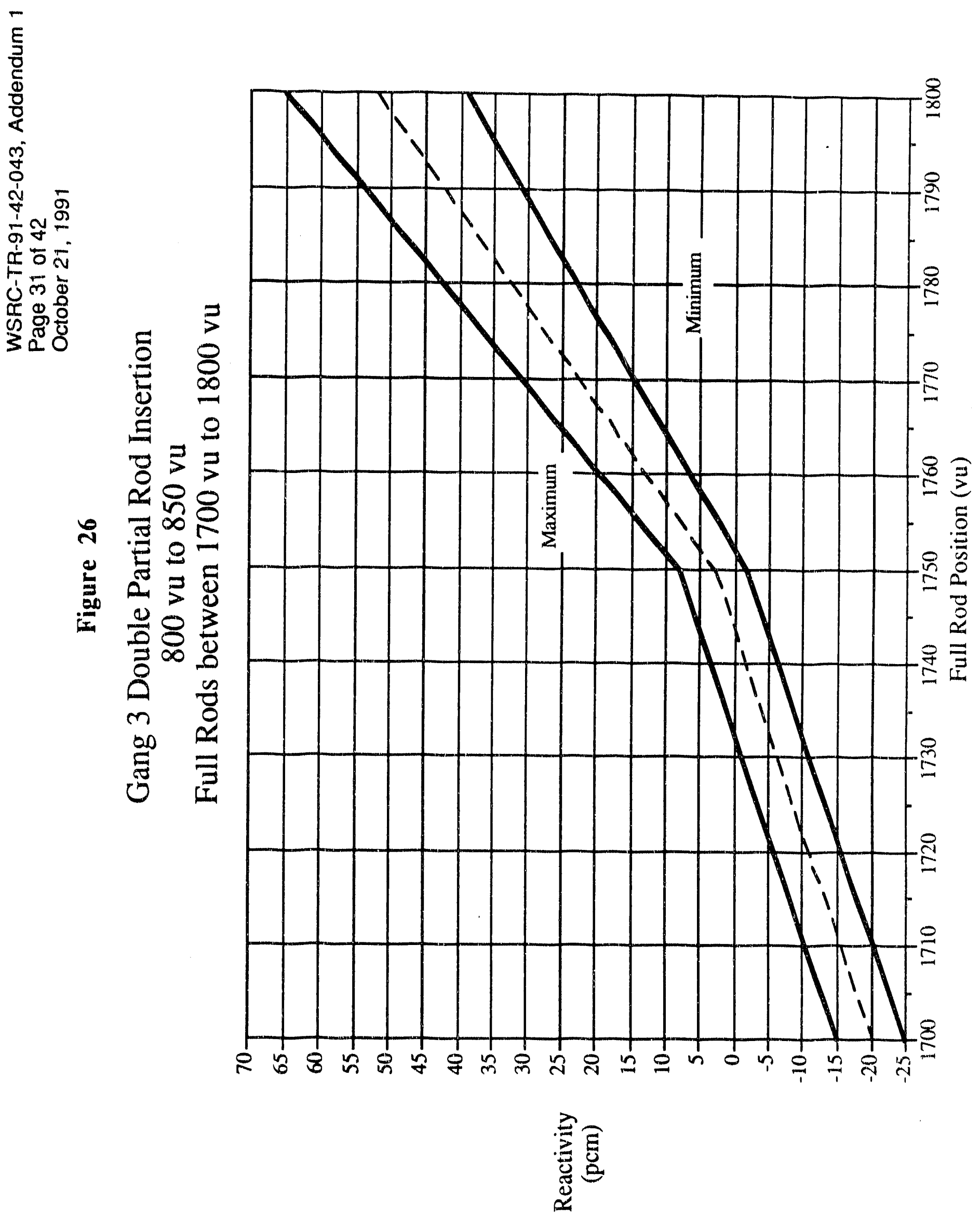




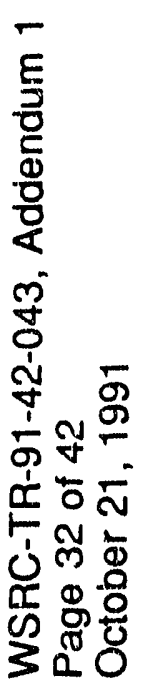

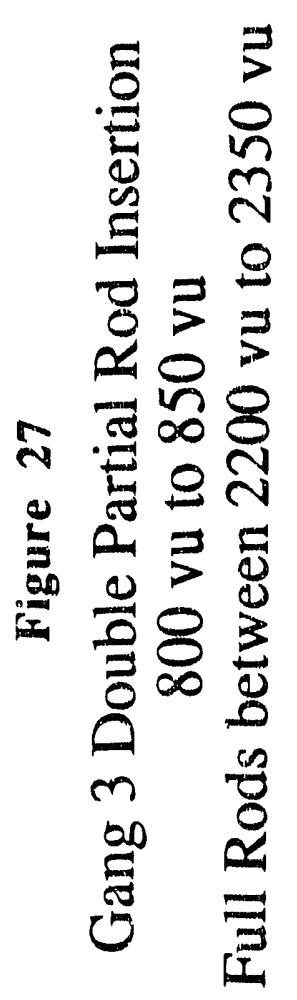

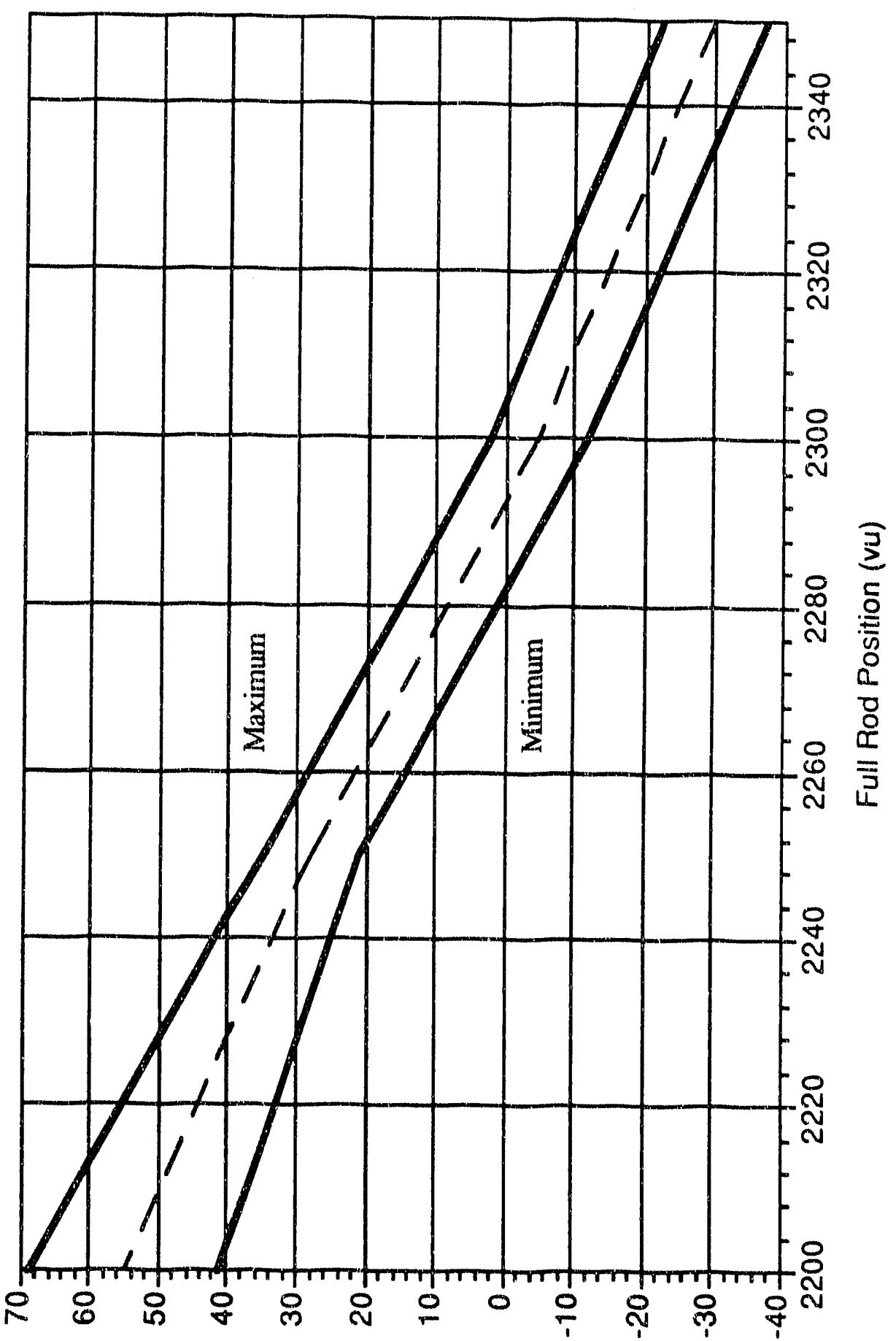

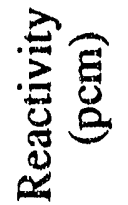


WSRC-TR-91-42-043, Addendum 1

Page 33 of 42

October 21, 1991

Figure 28

K-effective vs Full Rod Position Double Partial Rods at 800 vu

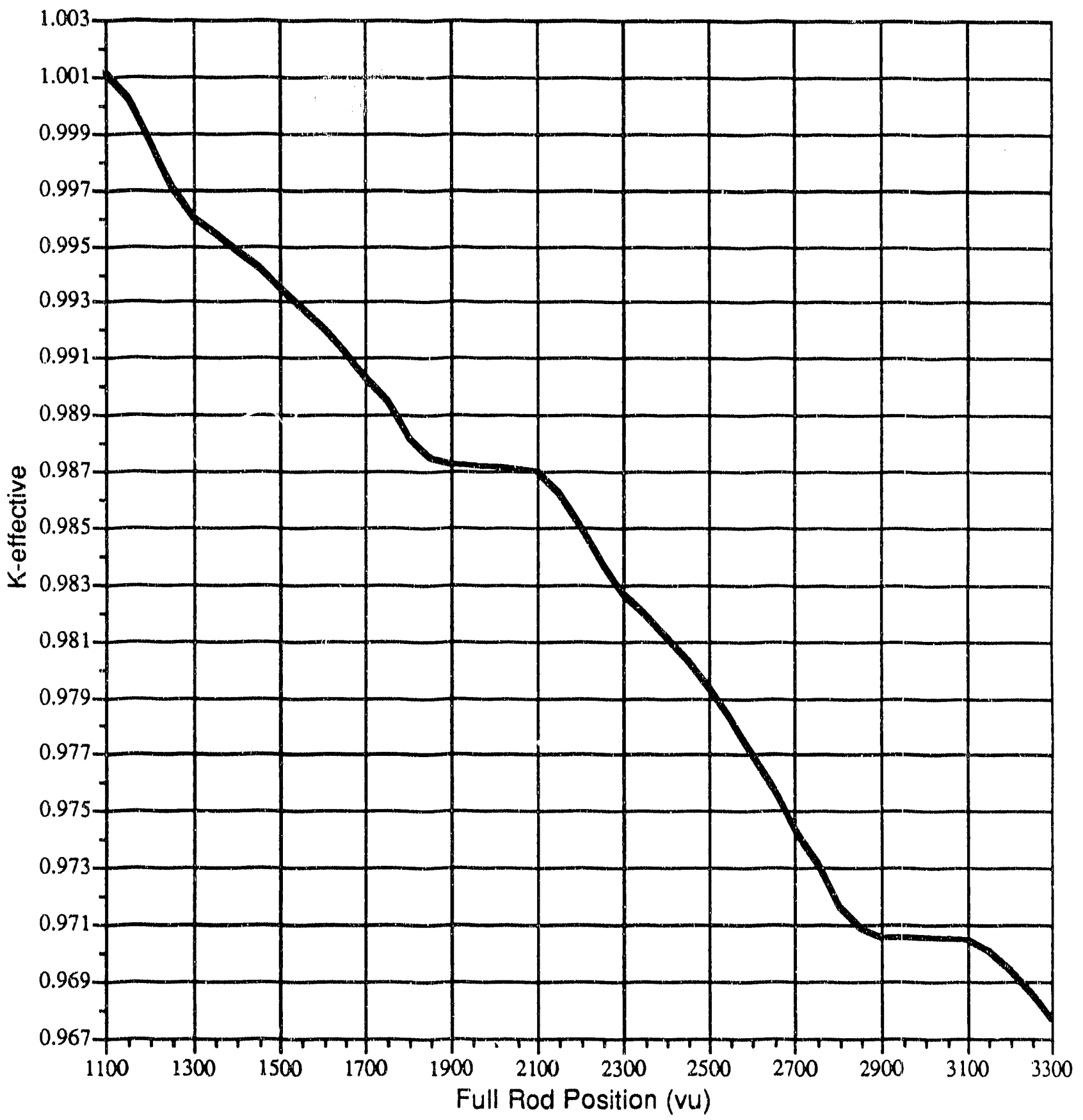


WSRC-TR-91-42-043, Addendum 1

Page 34 of 42

October 21, 1991

Figure 29

Full Control Rod Withdrawa! - 50 vu Double Partial Control Rods at 800 vu

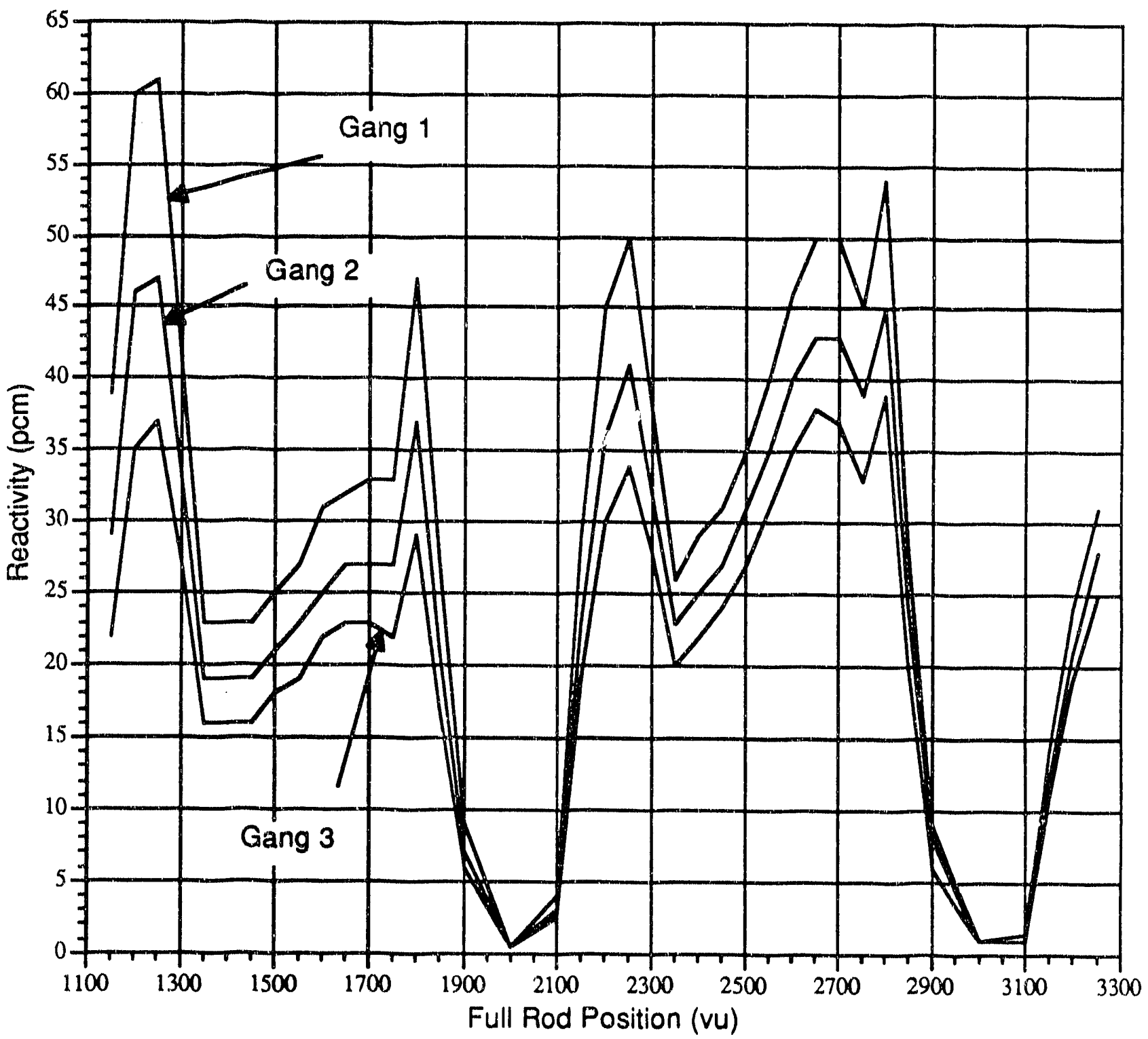


WSRC-TR-91-42-043, Addendum 1

Page 35 of 42

October 21, 1991

Figure 30

Full Rod Withdrawal - 10 PCM Reactivity Double Partial Control Rods at 800 vu

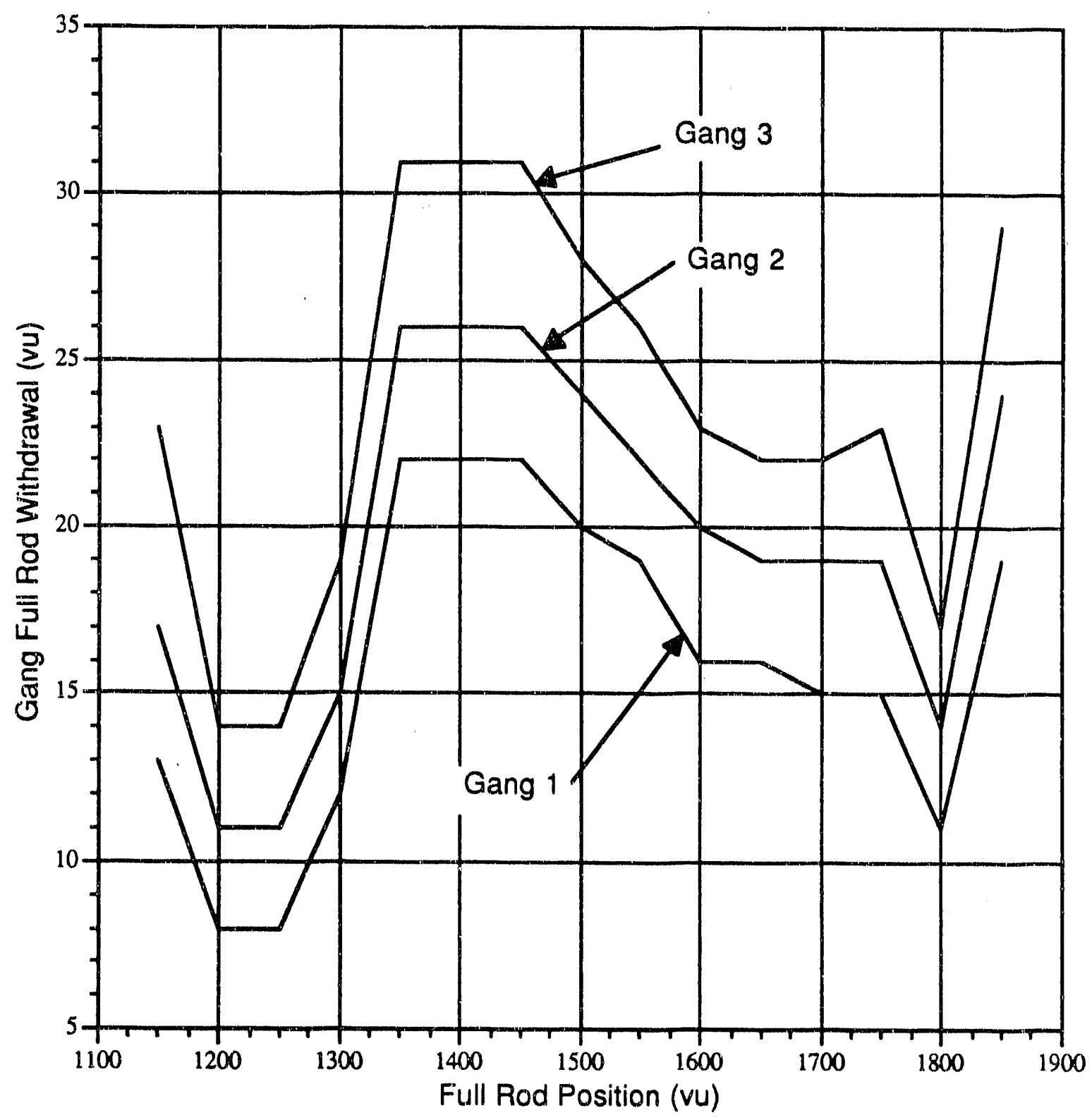


WSRC-TR-91-42-043, Addendum 1

Page 36 of 42

October 21, 1991

Figure 31

Full Rod Withdrawal - 10 PCM Reactivity Double Partial Control Rods at 800 vu

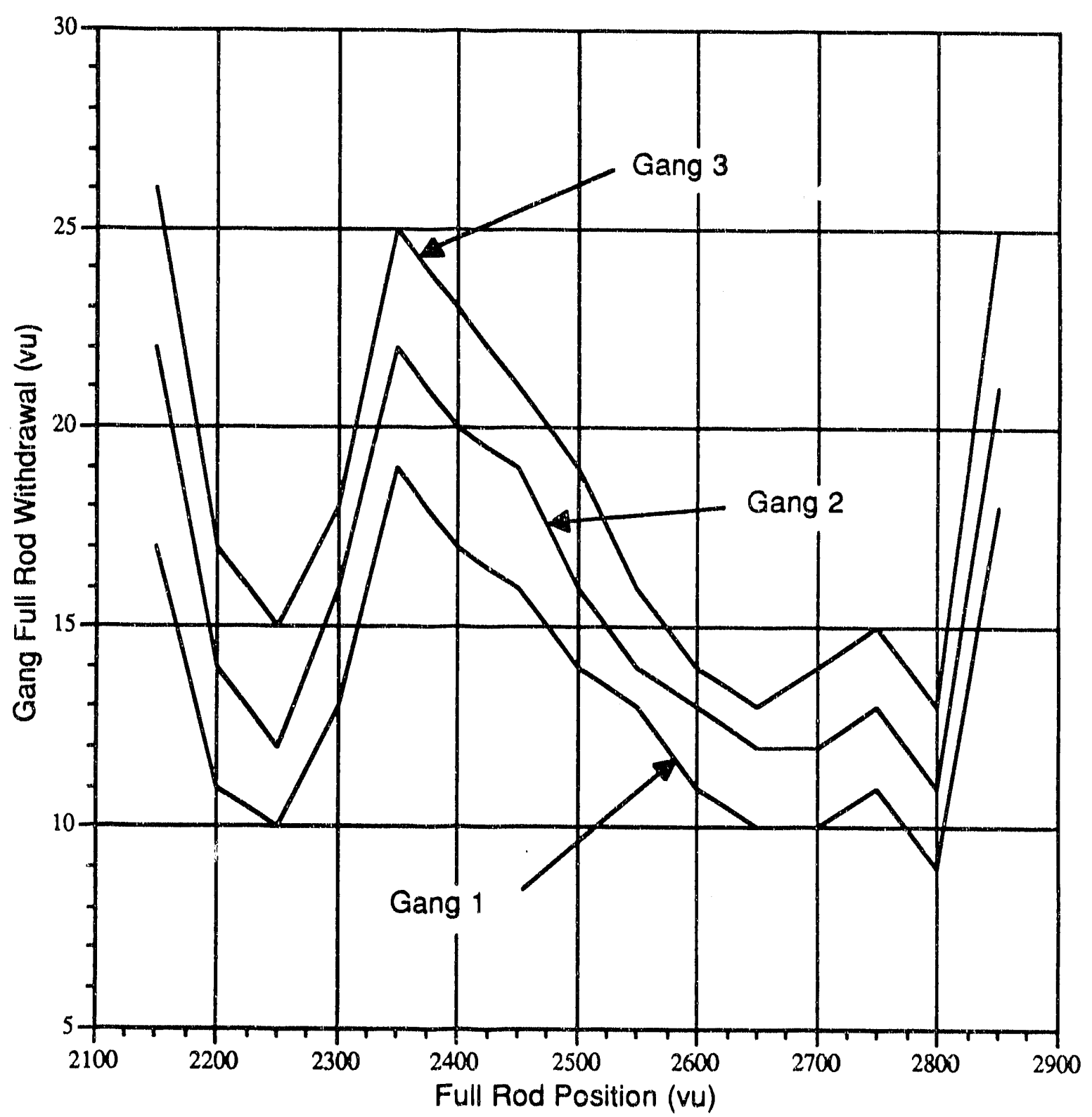


WSRC-TR-91-42-043, Addendum 1

Page 37 of 42

October 21, 1991

Figure 32

Full Rod Withdrawal - 10 PCM Reactivity Double Partial Control Rods at 800 vu

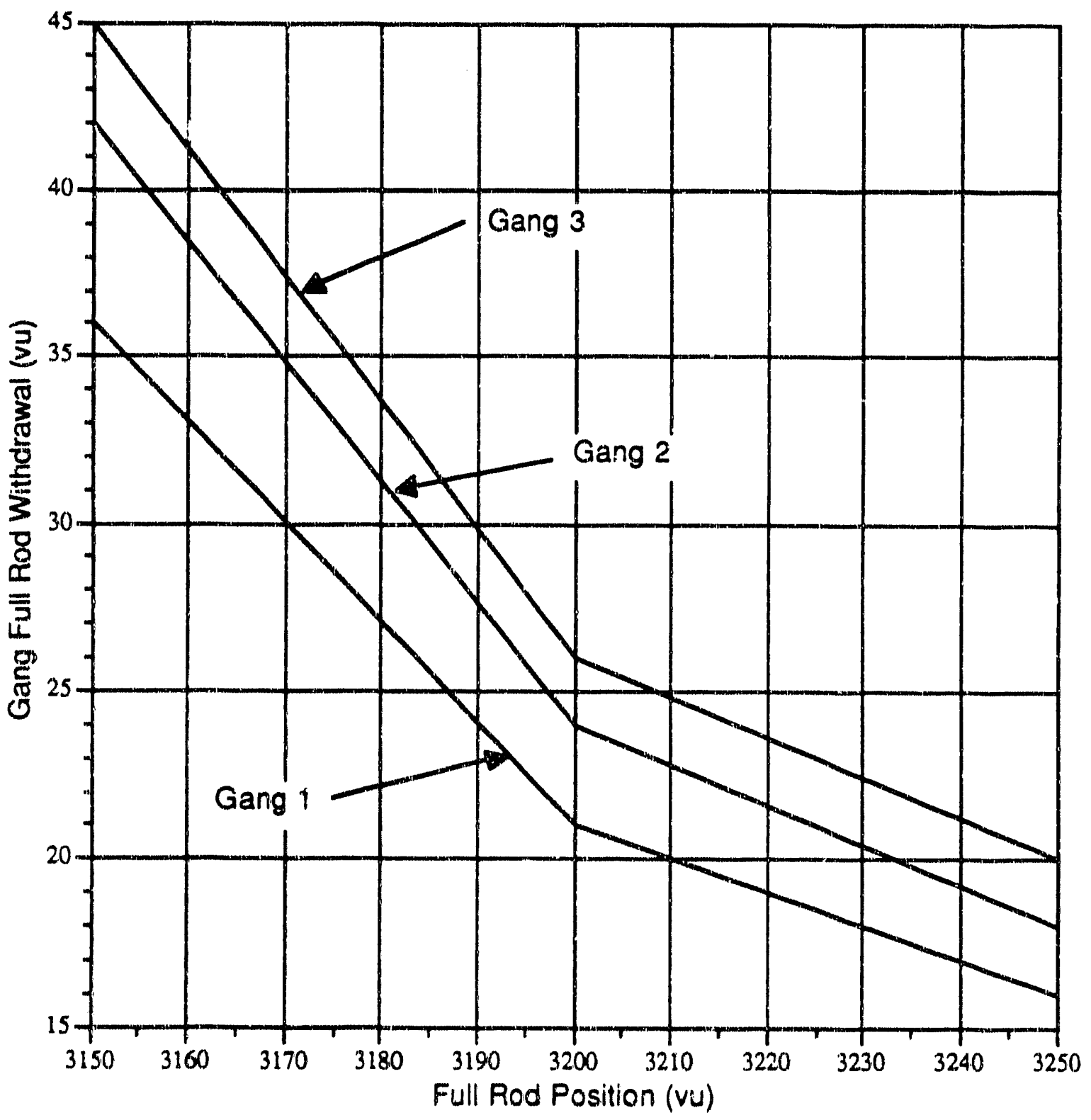


WSRC-TR-91-42-043, Addendum 1

Page 38 of 42

October 21, 1991

Figure 33

Full Rod Withdrawal - 20 PCM Reactivity Double Partial Control Rods at $800 \mathrm{vu}$

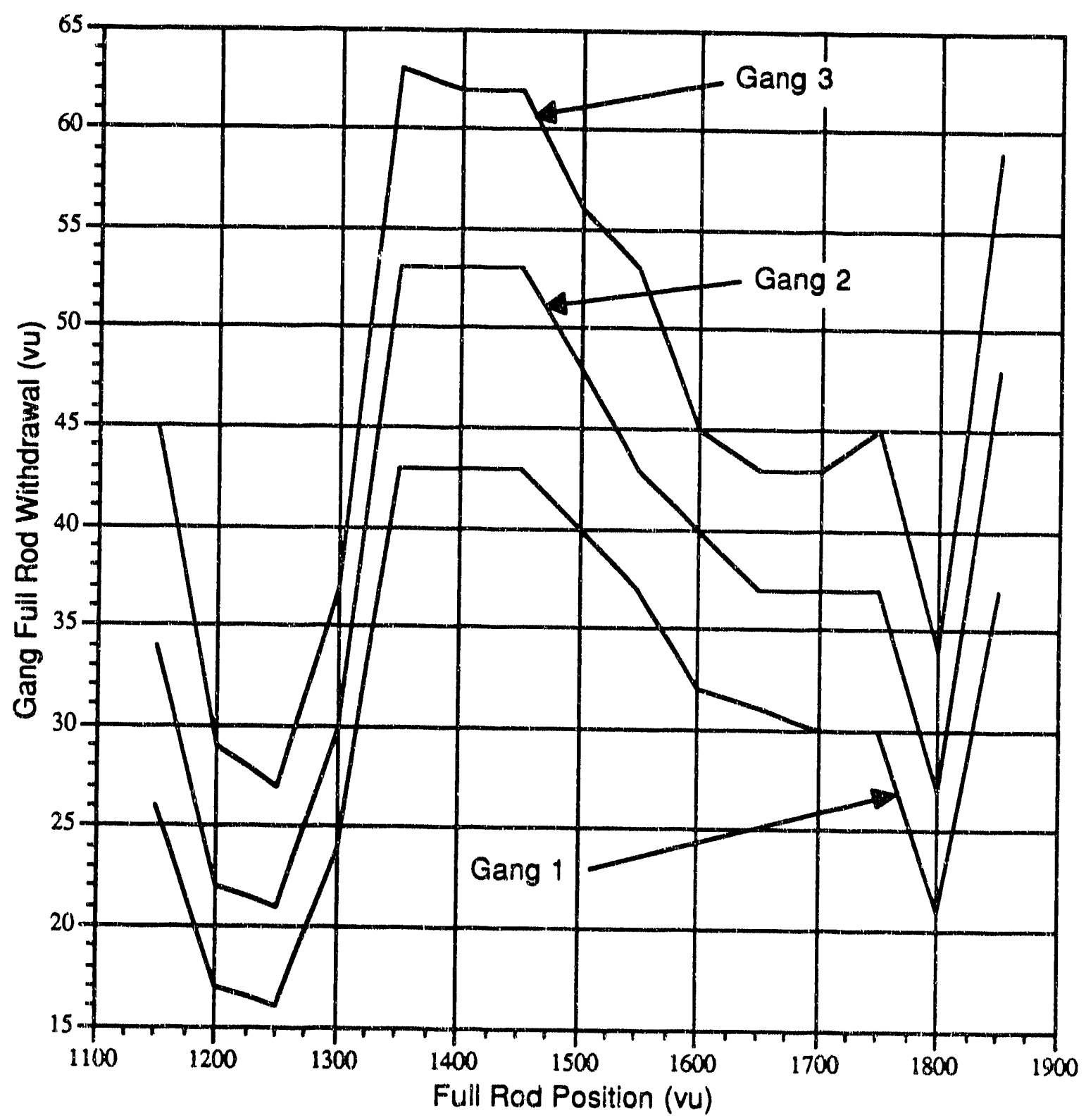


WSRC-TR-91-42-043, Addendum 1

Page 39 of 42

October 21, 1991

Figure 34

Full Rod Withdrawal - 20 PCM Reactivity Double Partial Control Rods at $800 \mathrm{vu}$

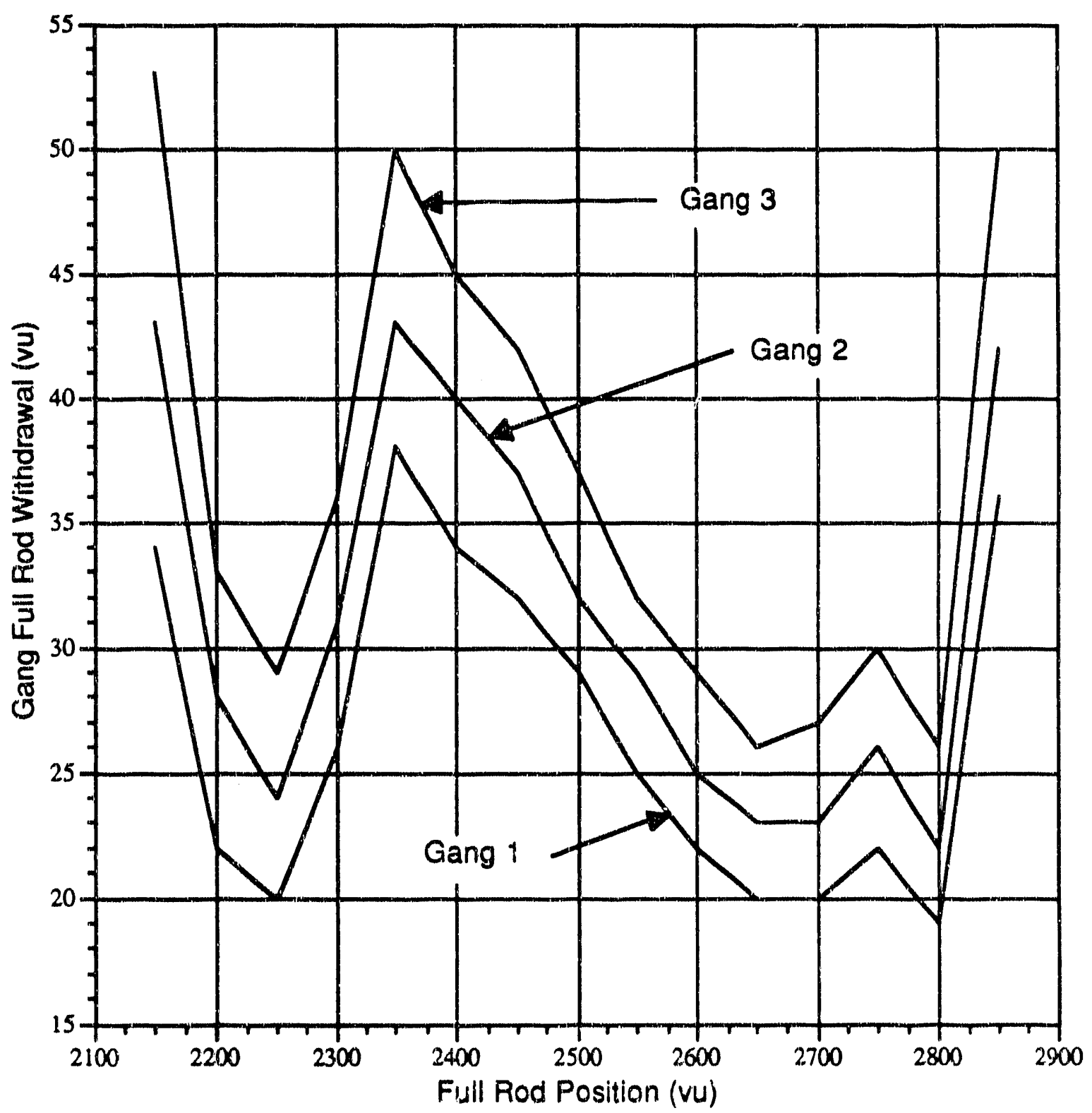


WSRC-TR-91-42-043, Addendum 1

Page 40 of 42

October 21, 1991

Figure 35

Full Rod Withdrawal - 20 PCM Reactivity

Double Partial Control Rods at $800 \mathrm{vu}$

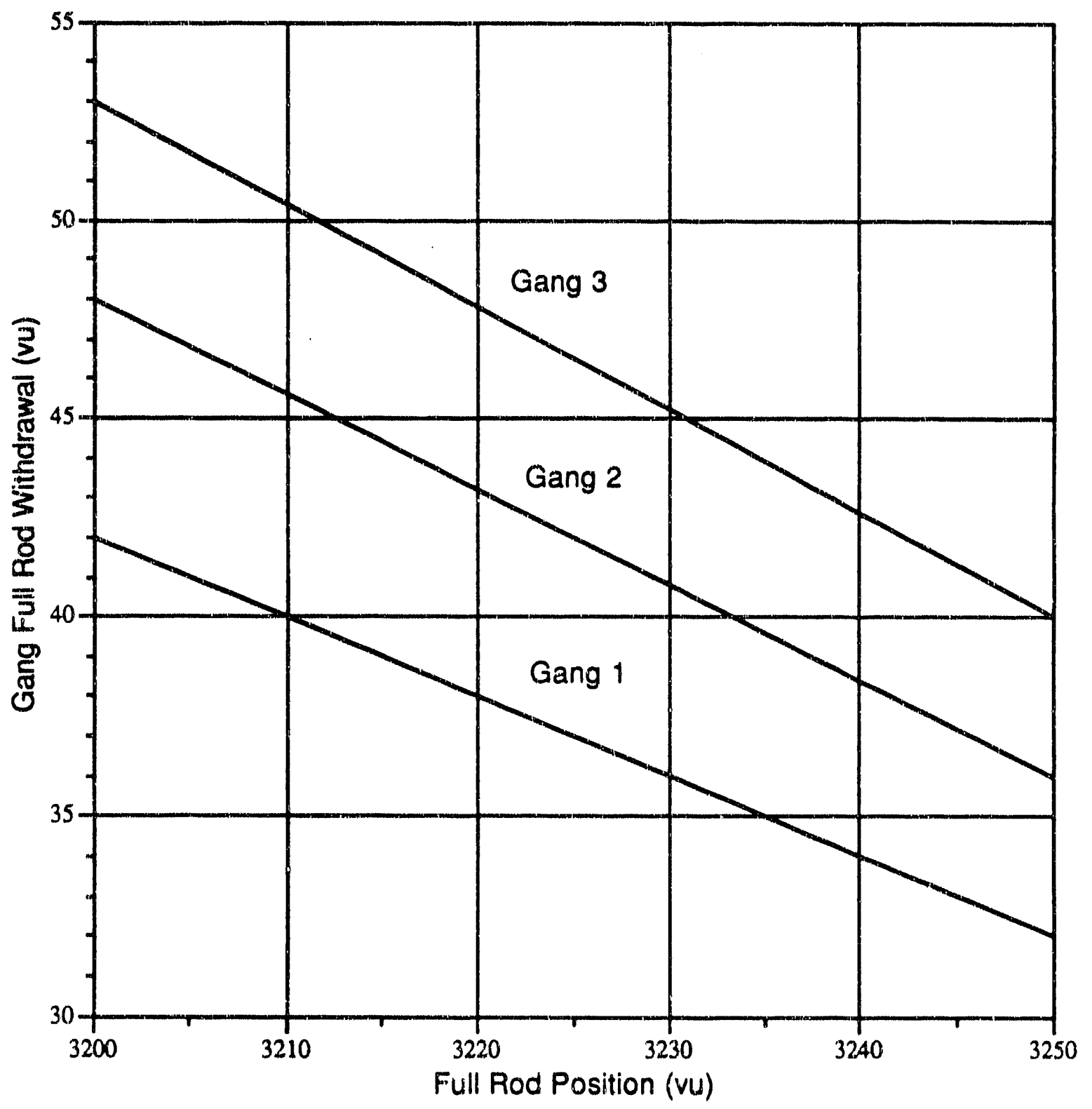


WSRC-TR-91-42-043, Addendum 1

Page 41 of 42

October 21, 1991

Figure 36

Full Rod Withdrawal - 30 PCM Reactivity Double Partial Control Rods at $800 \mathrm{vu}$

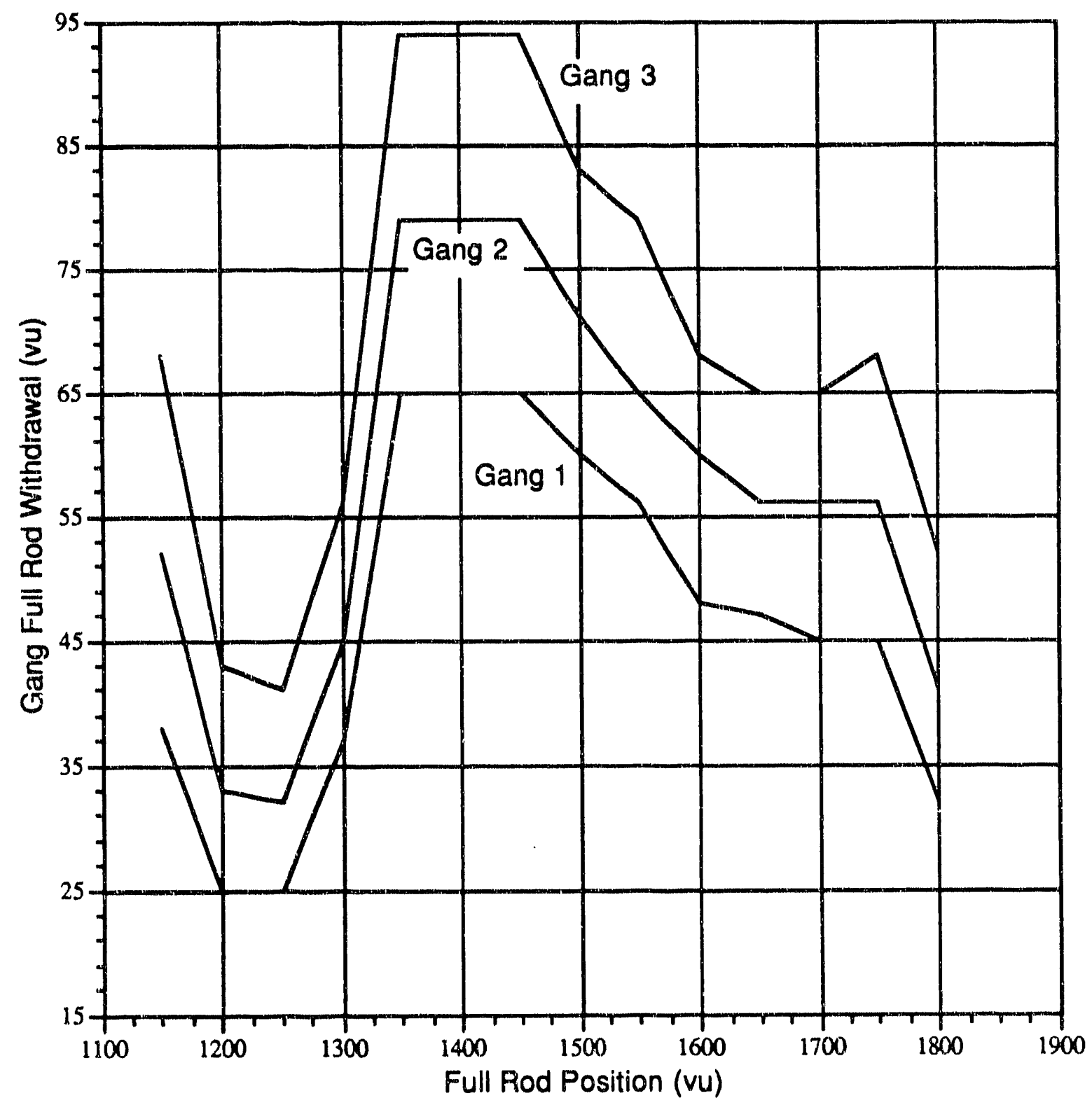


WSRC-TR-91-42-043, Addendum 1
Page 42 of 42

October 21, 1991

Figure 37

Full Rod Withdrawal - 30 PCM Reactivity Double Partial Control Rods at $800 \mathrm{vu}$

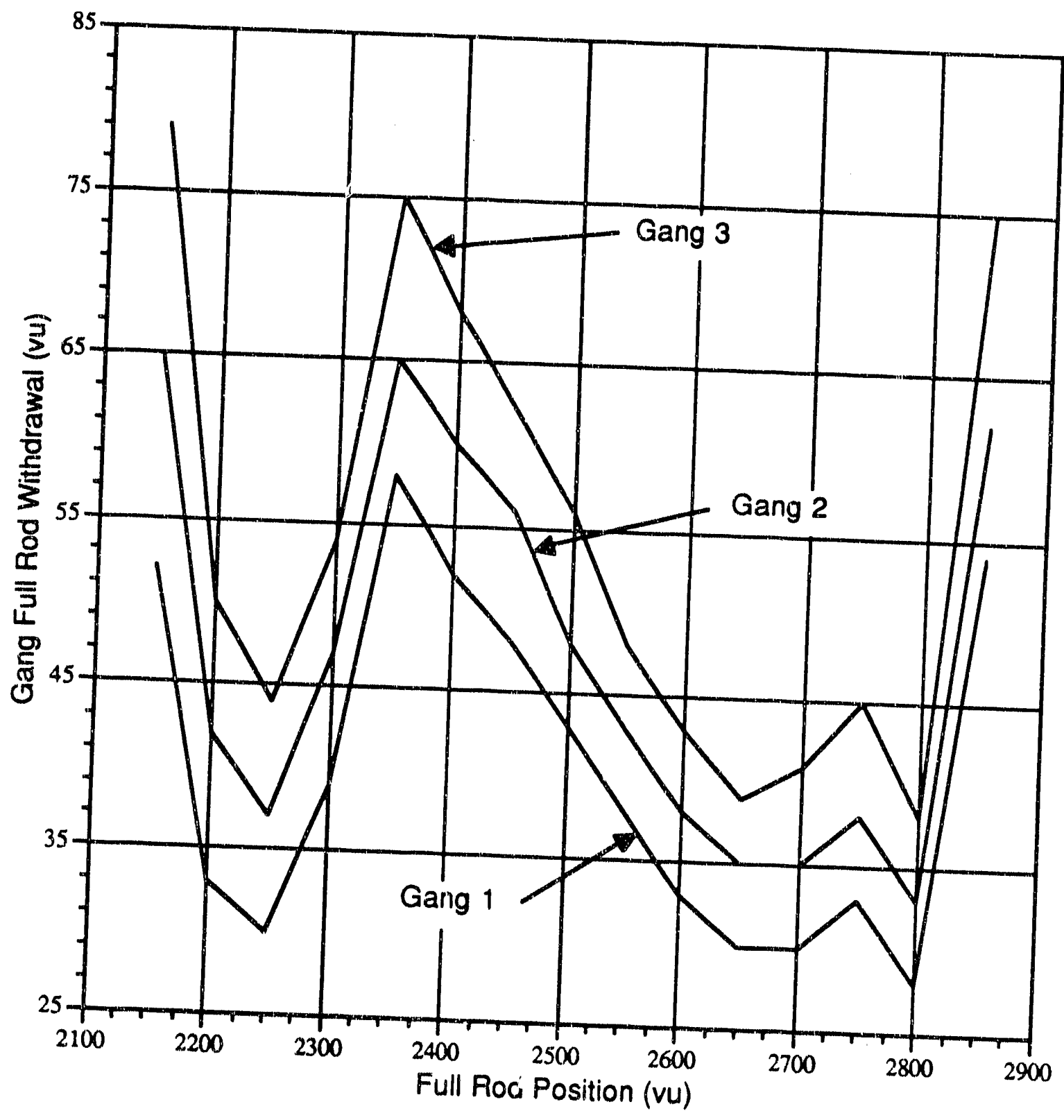


